\title{
PODER Y PRESTIGIO EN LOS ANDES CENTRO-SUR. UNA VISIÓN A TRAVÉS DE LAS PINTURAS DE ESCUTIFORMES EN GUACHIPAS (NOROESTE ARGENTINO)
}

\section{POWER AND PRESTIGE IN THE SOUTH-CENTRAL ANDES. AN APPROACH BASED ON THE SHIELD-SHAPE PAINTINGS OF GUACHIPAS (NORTHWESTERN ARGENTINA)}

\author{
M. Mercedes Podestá*, Diana S. \\ ROLANDI ${ }^{*}$, MIRTA SANTONI ***, \\ ANAHÍ RE* $* * *$, MARÍA PÍA FALCHI ${ }^{*} * * * *$, \\ MARCELO A. TORRES $* * * * * * \&$

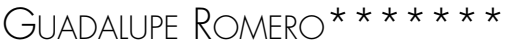

Este trabajo presenta un análisis del motivo escutiforme en los sitios emplazados en dos sectores de la microrregión Guachipas, Salta (Noroeste Argentino). Se revisa la dispersión de este motivo en contextos arqueológicos del Noroeste argentino y Norte de Chile y su asignación cronológica a los momentos del Tardío (Desarrollos Regionales e Inka), y se discuten las distintas posturas respecto de la interpretación de estas representaciones. Se evalúa la posibilidad de asumir estas representaciones como símbolos de poder y prestigio que recaen en individuos que representan la nueva jerarquía social durante el Tardío en los Andes centro-sur.

Palabras clave: arte rupestre, escutiforme, estética, Tardío, Noroeste Argentino, Norte de Chile.

This article presents a detailed analysis of the shield-shape motif in two areas in the Guachipas region, Salta (north western Argentina). The dispersion of this representation in archeological contexts from Northwestern Argentina and North Chile, and its chronological order to the Tardío (Desarrollos Regionales and Inka periods) is debated. The possibility of considering these motifs as symbols of power and prestige of individuals that represent the new hierarchy during those periods in the center-south Andes, is evaluated.

Key words: rock art, shield-shape motif, aesthetic, Late period, Northwestern Argentina, North of Chile.

\section{INTRODUCCIÓN}

En este trabajo se abordará el análisis de una representación particular, el escutiforme, que se distingue ampliamente dentro del extenso repertorio rupestre del área seleccionada para este estudio: la microrregión Guachipas, provincia de Salta, Noroeste Argentino (NOA). La singularidad de este motivo reside no solo en sus características estéticas, a las que nos vamos a referir con cierto detalle, sino también en la amplia variabilidad y densidad que registra en dicha región.

Se define el escutiforme como una representación cuya forma general se asemeja a una doble hacha con una acentuada angostura en la parte media y una expansión en la parte superior e inferior del cuerpo, o bien con largas prolongaciones en la parte superior de la figura. Como señala Aschero (2000), es la entalladura lo que distingue nítidamente al escutiforme del uncu, otra representación característica del arte rupestre andino que representa la típica vestimenta indígena y que se asocia frecuentemente con los escutiformes. Esta forma básica de escutiforme presenta una amplia gama de variaciones que se irá describiendo a lo largo de este trabajo en lo concerniente a las representaciones de este tipo halladas en Guachipas, entre las que se incluyen

* M.Mercedes Podestá, Instituto Nacional de Antropología y Pensamiento Latinoamericano (INAPL), Buenos Aires, email: mercedespodesta@yahoo.com

* Diana Rolandi, INAPL, Buenos Aires, email: rolandidiana@gmail.com

*** Mirta Santoni, Museo de Antropología de Salta-Argentina, Salta, email: mesantoni@fibertel.com.ar

*****: Anahí Re, INAPL, CONICET-UBA, Buenos Aires, email: anahire1@gmail.com

*****áa Falchi, INAPL, Buenos Aires, email: mpiafalchi@gmail.com

**:* Marcelo Torres, INAPL, Buenos Aires, email: marcel_art@yahoo.com.ar

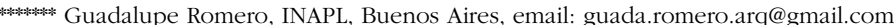


algunas formas sin la escotadura medial, o bien con una angostura apenas esbozada.

Adherimos a la interpretación de varios colegas que nos precedieron en esta temática, que considera el escutiforme como un tipo de representación humana con rasgos corporales identificatorios o sin ellos. Los escutiformes ya aparecen en la literatura arqueológica temprana del NOA con diferentes nombres, siendo el de escudo el primeramente usado (Ambrosetti 1895, 1904; Quiroga 1931). Luego esta nominación fue variando en busca de una connotación más antropomorfa, es así que la bibliografía más reciente, que da cuenta de la permanencia del tema en la arqueología del Tardío en la circumpuna, ${ }^{1}$ incorpora los nombres de: personaje-escudo (Aschero 1979), hombres-escudo (Santoni \& Xamena 1995), antropomorfo escutiforme (Ruiz \& Chorolque 2007) y hombres hacha (Montt 2005; Montt \& Pimentel 2009).

Las representaciones de escutiformes son propias del arte rupestre del Período Agroalfarero Tardío o de Desarrollos Regionales (Argentina) o Intermedio Tardío (Chile) y han sido documentadas mayoritariamente en aleros y abrigos y, en menor medida, en bloques y superficies rocosas al aire libre; además, existe un caso excepcional hallado en contexto de chullpas (Ruiz \& Chorolque 2007). No se registran ejemplos anteriores a este período que se inicia alrededor de los 900 años DC. De acuerdo con diversos autores, esta representación se extiende hasta la expansión inkaica en el NOA y Norte de Chile perdurando, de esta manera, hasta los 1530 años DC (Montt 2005; Montt \& Pimentel 2009; Troncoso 2011). No se descarta que la relevancia simbólica de los escutiformes continuara hasta los momentos de contacto hispano-indígena, tal como se expresa en la microrregión Guachipas.

Las sociedades de los Períodos de Desarrollos Regionales e Inka, productoras de estas imágenes, se caracterizaron por un fuerte crecimiento demográfico y la aparición de sistemas políticos con identidad propia y control sobre diferentes territorios. La producción agrícola y ganadera se encontraba en su apogeo y los enfrentamientos debido al control de los recursos provocaron alianzas y rivalidades que tiñeron estos siglos de un tono bélico intenso (Tarragó 2000). En este contexto, en el valle de Yocavil o Santa María se desarrolló un estilo ampliamente reconocido por sus urnas funerarias que también se manifestó en Pampa Grande, situada al sur de nuestra microrregión de estudio. El Estilo santamariano no solo se expresó en las urnas, sino que se desplegó hacia otros soportes, entre los cuales se incluye el arte rupestre. En este sentido, asumimos que parte de las pinturas de Guachipas está directamente relacionada con la estilística santamariana.
A partir de la información aquí presentada cabe destacar que la microrregión Guachipas conforma la mayor concentración de escutiformes en los Andes centro-sur. ${ }^{2}$ En este trabajo se incluye el análisis de casi 400 representaciones plasmadas en 26 aleros localizados en dos sectores de las serranías de Guachipas: Quebrada de Ablomé y Las Juntas. Se busca con ello contribuir en el análisis de esta representación aportando una novedosa información que permanece en su mayoría inédita, a pesar de los esfuerzos de algunos investigadores que nos precedieron (Santoni \& Xamena 1995). A fin de caracterizar estos motivos, en este trabajo se evaluarán las características estéticas de los escutiformes de la región.

La estética refiere a la capacidad de los objetos, mediante ciertas cualidades formales, de generar una respuesta sensorial en las personas (Gosden 2001). Según estas características, pueden afectar a grupos humanos más pequeños o más grandes. De esta manera, no todos los objetos son igual de efectivos para generar una respuesta, ya que algunos atraen más atención y respeto. Debido a que los motivos rupestres implican principalmente el sentido de la vista, tienen el potencial de llegar a un grupo más numeroso de personas. Además, dado que su soporte es fijo, fueron ejecutados para ser apreciados en ese mismo lugar y se integran en su entorno natural (Heyd 2003). Debido a que el arte rupestre constituye uno de los componentes más visibles y perdurables del registro arqueológico y tiene el potencial de ser encontrado por numerosos individuos, se considera la posibilidad de que se hayan expresado cuestiones sociopolíticas a través del mismo.

No obstante, tal como queda evidenciado por la literatura arqueológica (Aschero 2000; Montt 2005; Podestá et al. 2005; Martel 2010, entre otras), se reconoce que no todas las imágenes rupestres tienen las mismas propiedades estéticas. Así, en función de sus características tanto formales como técnicas y a su emplazamiento, se entiende que pueden haber desempeñado distintos roles y haber sido ejecutadas, observadas o apreciadas por diferentes individuos o grupos.

En este artículo se presenta la información disponible sobre los escutiformes de la microrregión Guachipas y se evalúan sus características, a fin de ahondar en el papel cumplido por estas representaciones en las sociedades del Tardío del NOA. En primer lugar, se considera su frecuencia y distribución en el área de estudio. Estas variables permitirán evaluar el contexto de ejecución de estos motivos e inferir su potencial alcance. Asimismo, su ubicación en el soporte rocoso de los sitios arqueológicos es un indicador de su visibilidad y accesibilidad. Luego se discute su morfología, tanto en términos de contornos y diseños internos, como presencia/ausencia 
de rasgos humanos y atuendos. También se presenta la información disponible sobre dimensiones de estos motivos y tonalidades de las pinturas empleadas. El estudio de estas variables en su conjunto permitirá evaluar la capacidad de estos motivos de impactar en los grupos humanos, así como arrojar luz sobre los costos en términos de tiempo, esfuerzo y materiales para sus productores. Por último, se consideran los temas en los que están incluidos estos motivos y las superposiciones en que están involucrados, a fin de profundizar en el contexto de ejecución y uso de estas representaciones.

Cabe destacar que la evaluación de las propiedades estéticas de objetos producidos por sociedades distanciadas en tiempo y espacio presenta dificultades, ya que no se conoce acabadamente su contexto cultural (Heyd 2003, 2012). Aquí se presenta solamente un acercamiento a esta temática a partir del análisis de determinadas variables que fueron seleccionadas en esta instancia y que permiten una primera aproximación al tema de estudio.

Retomando las ideas antes mencionadas en relación con el rol potencial de los escutiformes dentro del contexto social donde fueron creadas, sostenemos que estas imágenes estuvieron de alguna manera implicadas en las prácticas sociopolíticas del Tardío en el NOA y Norte de Chile. En estas prácticas fue de vital importancia contar con una imaginería relacionada con atributos de estatus, prestigio y poder que, como iremos viendo a lo largo del trabajo, se ajusta perfectamente al valor estético de los escutiformes.

\section{LOS ESCUTIFORMES EN LOS ANDES CENTRO-SUR}

\section{Espacio geográfico y cronología}

La dispersión del motivo escutiforme es amplia dentro del área surandina, localizándose en gran parte del NOA y Norte de Chile (fig. 1) (Ambrosetti 1895; Boman 1908; Quiroga 1931; Aschero 1979, 2000; Santoni \& Xamena 1995; Berenguer 2004a, 2009; Montt 2005; Podestá et al. 2005; Martel 2009, 2010; Montt \& Pimentel 2009; de Hoyos 2013), si bien recientemente se dieron a conocer algunas representaciones excepcionales alejadas de estas áreas (Troncoso 2011).

En el NOA, los escutiformes tienen una presencia ubicua. En la provincia de Salta, además de los sitios del departamento de Guachipas, que serán analizados con más detalle, estos aparecen profusamente en los valles calchaquíes, específicamente en la región de Cafayate (Quiroga 1931; Ledesma \& Subelza 2012) y en el sitio Santa Bárbara localizado al oeste de la sierra de
Carahuasi y próximo al río homónimo. En ámbitos de esta misma sierra se encuentran los sitios Churcal y Río Pablo (Quiroga 1931). En el valle Calchaquí medio, el sitio Fuerte de Tacuil presenta escutiformes grabados emplazados en un ámbito bajo fuerte dominio inkaico (Williams et al. 2005). Hacia el noroeste, en la quebrada del Toro, sobresalen los escutiformes grabados sobre bloques de la quebrada de Tastil (Meninato 2008) y, en alturas de casi $4000 \mathrm{msnm}$, los del sitio Morritos Alero 2, asociados a contextos tardíos (Muscio 2010). Se destacan también las pinturas de la quebrada de la Quesera y Jume Rodero (valle de Amblayo) (Martel 2010; de Hoyos 2013), además de otras representaciones en Cachi.

Dejando los ambientes de puna y de valles y quebradas de Salta, los escutiformes también son frecuentes en las provincias de Jujuy y Catamarca. En la primera se han documentado en ambientes de puna, tanto en Barrancas como en el Pucara de Rinconada y sitios aledaños de donde proviene el caso de los escutiformes pintados en contexto de chullpas ya mencionado (Boman 1908; Ruiz \& Chorolque 2007). También se han registrado en sitios de la quebrada de Humahuaca, como los grabados de Los Pintados de Sapagua y Cerro Negro, y las pinturas de Kollpayoc (Fernández Distel 2001; Nielsen 2007). En la quebrada de Inca Cueva, en el borde oriental de la puna, los escutiformes integran el repertorio del Grupo Estilístico C1 definido en Inca Cueva 1. Se trata del grupo más reciente (Período de Desarrollos Regionales) de una secuencia pictórica que arranca varios miles de años antes del presente, definida originalmente por Aschero (1979), quien, dos décadas después de su primera definición y con el aporte de nueva evidencia, realizó una diacronización interna del Grupo Estilístico y ubicó a los escutiformes en el grupo C1-b, correspondiente a un momento prehispánico posiblemente vinculado a la presencia inka en el NOA (Aschero 2000).

La presencia de escutiformes se da también en ambientes de selva, como en el caso de la serranía de Calilegua (vertiente oriental andina), en contextos arqueológicos de los Períodos de Desarrollos Regionales e Inka dados a conocer recientemente (Cruz \& Jara 2011). En la provincia de Catamarca hay motivos escutiformes en Andaguala, Lorohuasi y en la Gran Gruta Grabada de Chiquimí (valle de Santa María) (Quiroga 1931). Son característicos también los escutiformes de Loconte en el valle del Hualfín, sitio que dio lugar -junto con el de Carahuasi (Salta) - a la definición del Estilo IV, la fase más tardía (momento preinkaico y contemporáneo a la expansión inkaica) de la secuencia de arte rupestre planteada por Lorandi (1966) para el NOA. El estilo fue retomado posteriormente como Estilo IV "De los escudos 


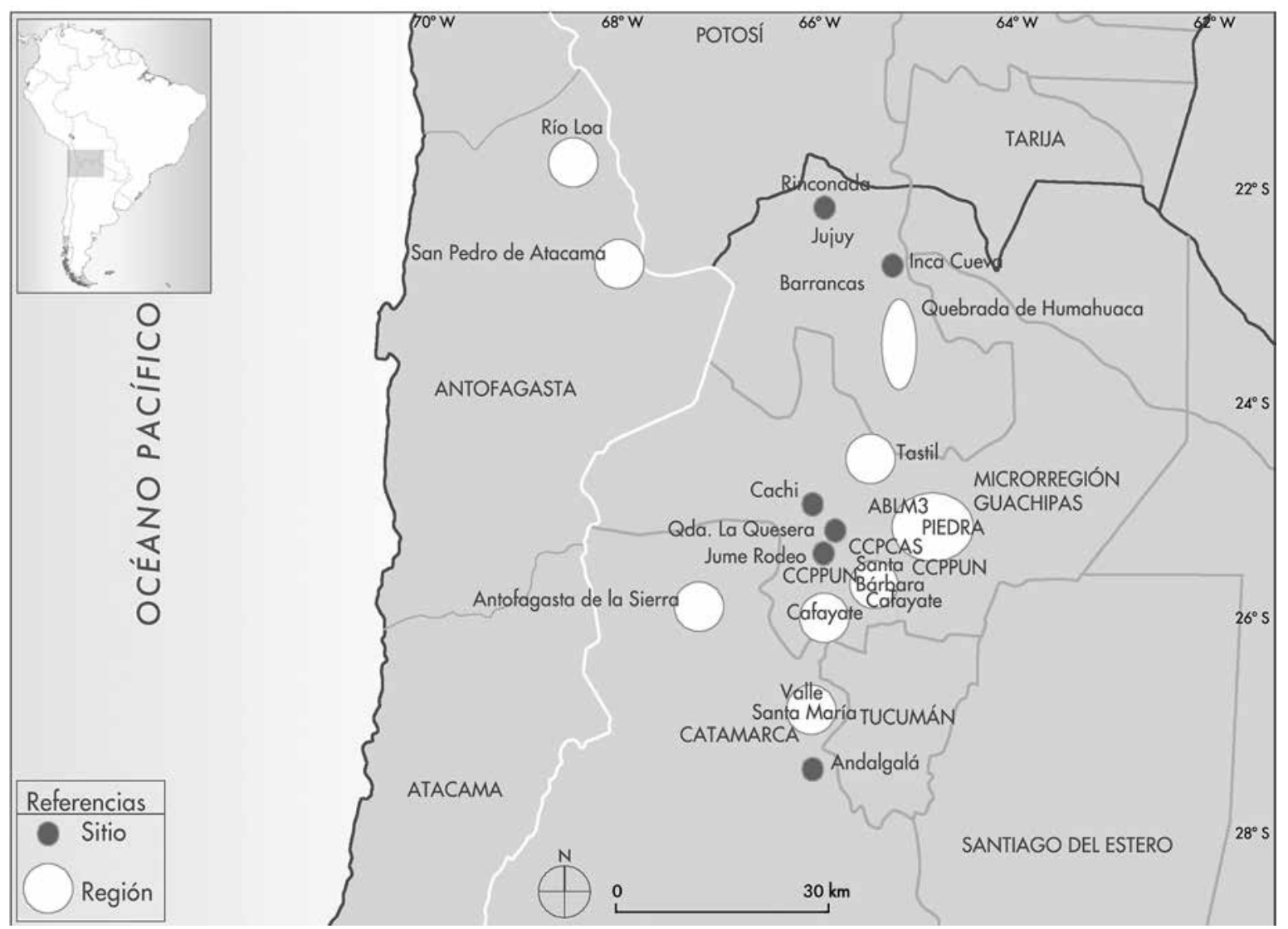

Figura 1. Sitios y regiones con representaciones de escutiformes en Andes Centro-Sur.

Figure 1. Sites and regions with shield-shape representations in the South-Central Andes.

o Loconte-Carahuasi" (González 1977). En ambientes puneños sobresale una importante concentración de sitios con escutiformes en la región de Antofagasta de la Sierra que, como en los anteriores casos, están asociados a las ocupaciones prehispánicas del Tardío (Ambrosetti 1904; Podestá 1986-1987; Falchi 1994; Aschero 2000; Martel 2009, 2010; de Hoyos 2013).

Atravesando la cordillera de los Andes hacia su vertiente occidental, en el Norte de Chile, los escutiformes están representados en dos sitios del sector Santa Bárbara del Alto río Loa, en la región del desierto de Atacama. Por otra parte, en la cuenca del río San Pedro, cerca de San Pedro de Atacama, se han registrado escutiformes en cinco sitios (Montt \& Pimentel 2009). El primer caso mencionado, que incluye las pinturas policromas del Alto Loa, fue la base para la definición del Estilo Santa Bárbara II (Berenguer 2004a). Este autor observa que los antropomorfos con traje y los escutiformes del estilo mencionado son los motivos más conspicuos que ocupan sectores centrales en los paneles y presentan mayores tamaños en comparación con otras representaciones, como las de los camélidos.
De allí que plantea la pérdida de valor de estas últimas frente a los escutiformes, observación compartida por otros autores en contextos arqueológicos de la vertiente oriental andina (Aschero 2000; Martel 2009). En cuanto a los aspectos cronológicos, Berenguer propone que las pinturas de escutiformes del río Loa procederían del NOA y se habrían ejecutado después del 1300 DC y con posterioridad a los grabados del Estilo Santa Bárbara I, con los cuales comparten los mismos sectores dentro de la rinconada de Santa Bárbara (Berenguer 2004a). En un comienzo, Berenguer reconoce un momento preinkaico para la ejecución de los escutiformes, si bien posteriormente enfatiza la cronología inkaica de estos y señala que podría tratarse de representaciones producidas por poblaciones movilizadas por los inkas para la explotación de yacimientos cupríferos en la región del Alto Loa (Berenguer 2004b).

Respecto de la cuenca del río San Pedro, Montt \& Pimentel (2009) observan que la decoración de los escutiformes pintados o grabados de los sitios Catarpe Acceso, Cuchabrache este, oeste y Norte y Chuschul es típicamente inkaica, destacándose la clave inka y la 
decoración en campos divididos por una doble diagonal cruzada, además de campos reticulares, tipo ajedrezado o damero. De esta manera, estos autores reconocen una autoría inkaica para estas representaciones en forma exclusiva.

Como mencionamos anteriormente, Troncoso (2011) da a conocer tres representaciones de "antropomorfos con cuerpos de lados cóncavos", que en este trabajo consideramos una de las tantas variantes de escutiformes. Otorga a estas, al igual que lo hacen Montt \& Pimentel (2009), una cronología inkaica con base en el contexto arqueológico en el cual se insertan estas imágenes y en la particular decoración que presentan. Lo peculiar de este hallazgo en el sitio Los Mellizos (valle del río Illapel, Norte semiárido de Chile) es su lejanía del área donde se ubican generalmente estos motivos, ya que los separan más de $1000 \mathrm{~km}$ de distancia.

Sugerimos la continuidad simbólica de los escutiformes durante los momentos de contacto hispano-indígena a través de una evidencia de carácter único que se registra en el sitio Las Planchadas (sector Las Juntas, Guachipas). Se trata de una agrupación de pinturas en donde interviene una representación de clara cronología hispano-indígena (caballo y jinete) asociada espacialmente a motivos de máscaras ${ }^{3}$ y escutiformes (fig. 2) que explicaremos con mayor detalle en el acápite referido a los temas.

Por último, interesa destacar que los escutiformes están representados no solo en el arte rupestre, sino también en una variedad de artefactos muebles emblemáticos hallados en Argentina, como calabazas pirograbadas, placas o discos de bronce, trompetas y peines de hueso, además de los cuantiosos casos pintados en las urnas santamarianas. En cuanto a estas últimas, en ocasiones aparecen escutiformes en diversos sectores, como en el que ilustramos, donde este motivo está pintado en el cuello de la urna. Otra manera peculiar de representar el escutiforme en la urna se expresa en el ejemplar del Museo de Antropología de Salta (fig. 3), donde la parte media e inferior de la urna en su conjunto adquiere la figura de un escutiforme. Como mencionan Santoni \& Xamena (1995), la forma general de muchas de las urnas santamarianas tipo Pampa Grande, halladas en la región homónima (sector sur de la microrregión Guachipas) y publicadas por Ambrosetti (1904), remite a la morfología del escutiforme. La mayor parte de los objetos muebles referidos son parte de contextos funerarios con cronologías radiocarbónicas bien establecidas que permiten reafirmar la asignación tardía de las representaciones de escutiformes. En Chile, los autores mencionan las calabazas de Lasana y Turi y las placas metálicas de Catarpe y Turi (ver citas en Montt \& Pimentel 2009) resaltando, en algunos casos, la procedencia de estos objetos desde el NOA en momentos tardíos, previos al contacto con el europeo.

\section{Referentes del escutiforme}

En cuanto al significado de los escutiformes, se han planteado diversas propuestas en búsqueda de dilucidar cuál es el referente material o ideológico que inspiró la producción de figuras escutiformes. Si bien estos fueron interpretados desde un primer momento como representaciones de escudos resaltando su valor emblemático (Ambrosetti 1895; Quiroga 1931), posteriormente diversos autores han señalado la poca semejanza de estas figuras con las vestimentas usadas como defensa durante los conflictos bélicos, entre ellos los escudos. A manera de síntesis, Berenguer (2004a y b, 2009) menciona las gruesas corazas (petos y espaldares), escudos de cuero con decoraciones en el anverso y armazón de madera en el reverso, como los reportados en cementerios de la región atacameña, y las túnicas de urdimbre curva (región de Tarapacá). Este inventario coincide en parte con el de Falchi (1994), que diferencia cuatro tipos de vestimenta al interpretar las imágenes de figuras humanas y escutiformes del arte rupestre tardío de Antofagasta de la Sierra (Catamarca, Argentina): el escudo, la coraza o peto confeccionado en cuero grueso de varios paños unidos por costuras de cuero, la camisa-coraza, prenda tejida de fibras vegetales y lana y, por último, el uncu o típica camiseta o túnica tejida de la región andina.

Los escutiformes no demuestran claros referentes en ninguna de las prendas mencionadas, sean las de uso cotidiano o de tipo defensivo. Esta postura es conclusiva para Montt \& Pimentel (2009), quienes señalan que la iconografía de la vestimenta escutiforme solo es visible en el soporte iconográfico (tanto rupestre como mueble) y que carecen de referente alguno en los vestuarios mortuorios. Cabe agregar que los escudos utilizados por los inkas, profusamente ilustrados por Guamán Poma de Ayala (ver Nielsen 2007: figs. 2, 3 y 5), son rectangulares y no presentan escotaduras, es decir, que poco se asimilan a la morfología de los escutiformes. Las referencias de hallazgos en tumbas de objetos interpretados como escudos son muy escasas. Palma (1997-1998), basándose en el registro funerario recuperado por Debenedetti en las excavaciones practicadas entre 1917 y 1918 en La Huerta de Huacalera (quebrada de Humahuaca, Jujuy), menciona el hallazgo de dos escudos de madera en tumbas jerarquizadas en asociación con objetos de prestigio, como hachuelas, topos, arcos, cinceles de bronce, discos, entre otros elementos. Lamentablemente se desconoce la forma 

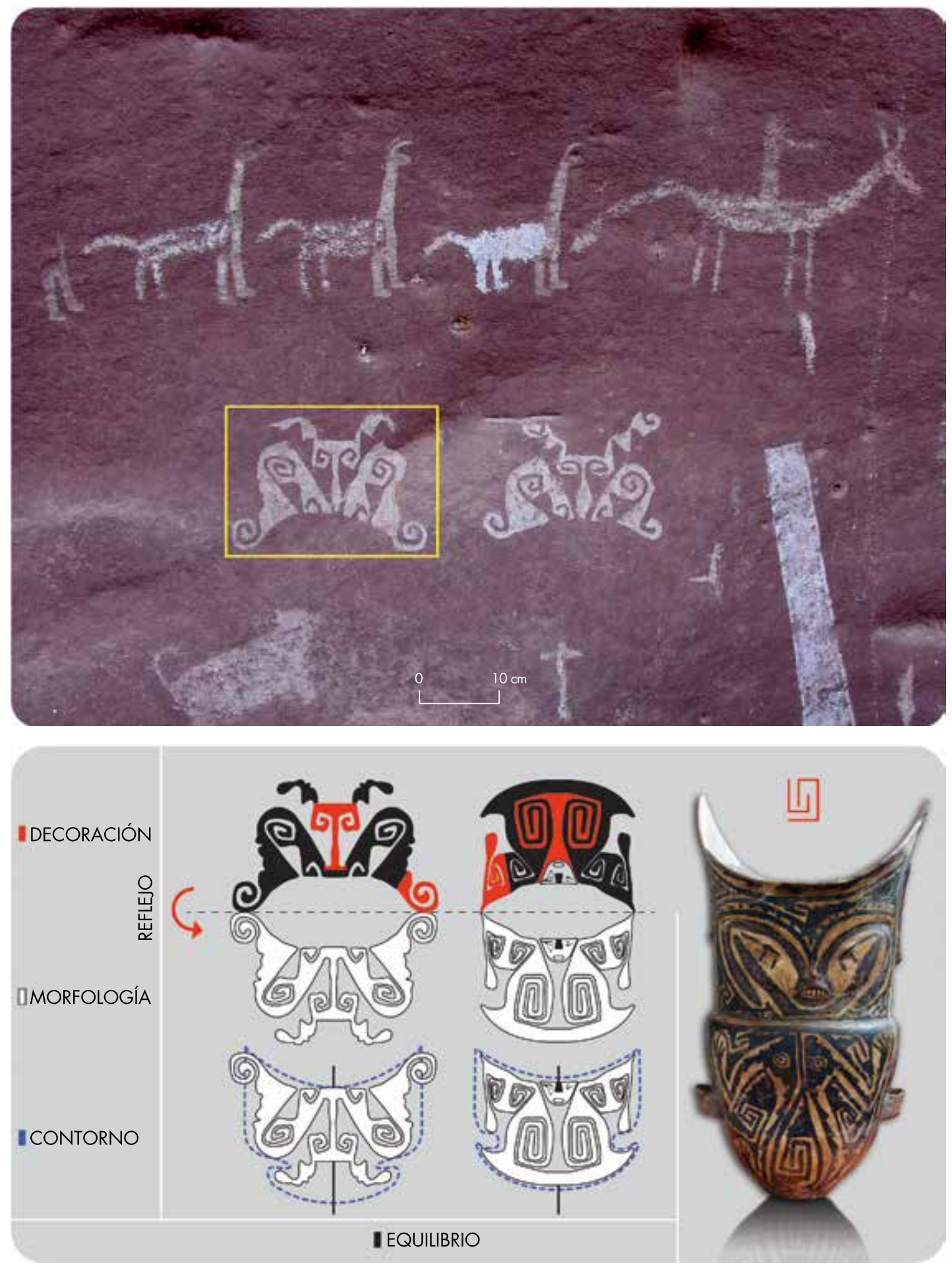

Figura 2. Sitio Las Planchadas, parte del Sector 3. Se observan máscaras asociadas a caballo con su jinete (parte superior). Abajo, detalle de una máscara invertida $180^{\circ}$ comparada con un escutiforme. A la derecha, urna santamariana con diseños de triángulos espiralados similares a los de las máscaras ( $\mathrm{N}^{\circ}$ 91-02-0770, Museo de Antropología de Salta).

Figure 2. Las Planchadas site, part of Sector 3. Note the masks associated with a horse and rider (upper portion). Below, detail of a mask inverted $180^{\circ}$ and compared with a shield-shape. On the right, a Santa Maria urn with spiraling triangular designs similar to those on the masks (No 91-02-0770, Museo de Antropología de Salta). 
a

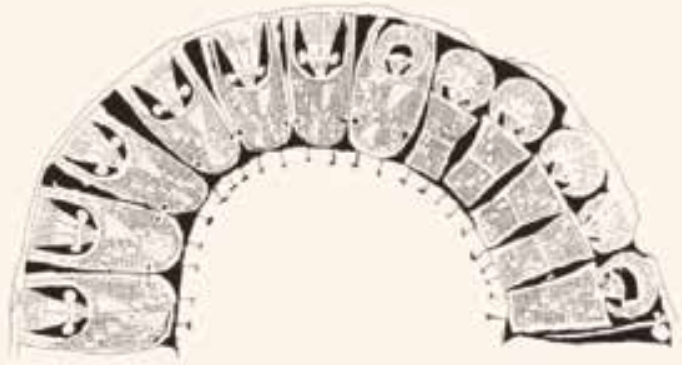

C

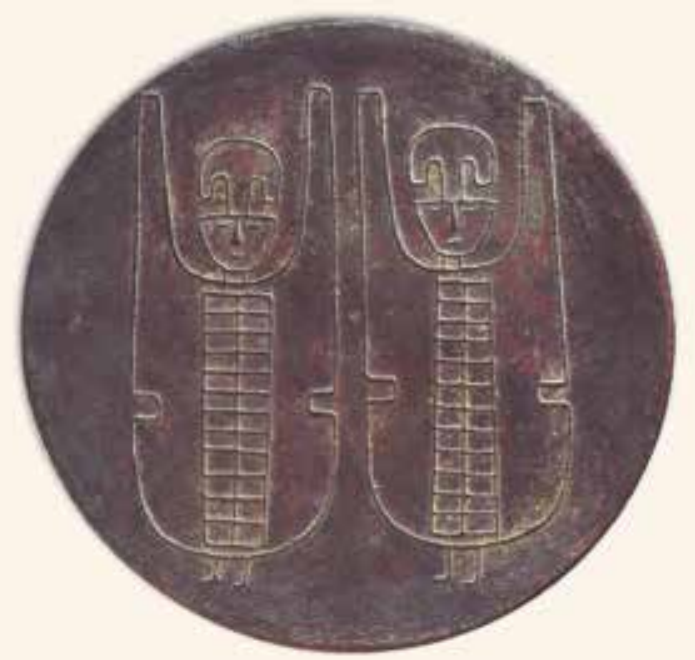

d

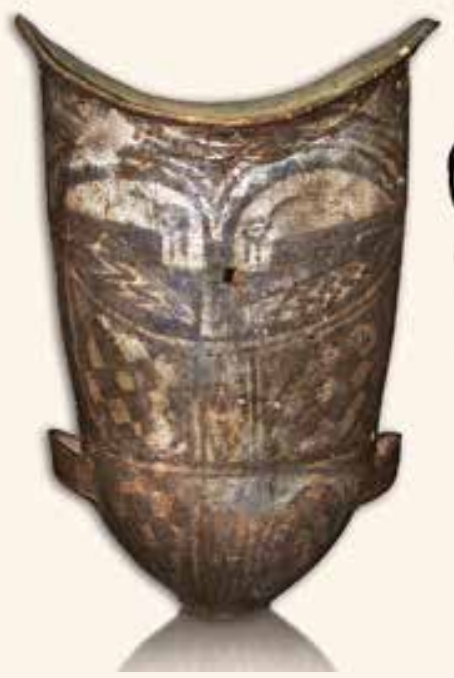

b

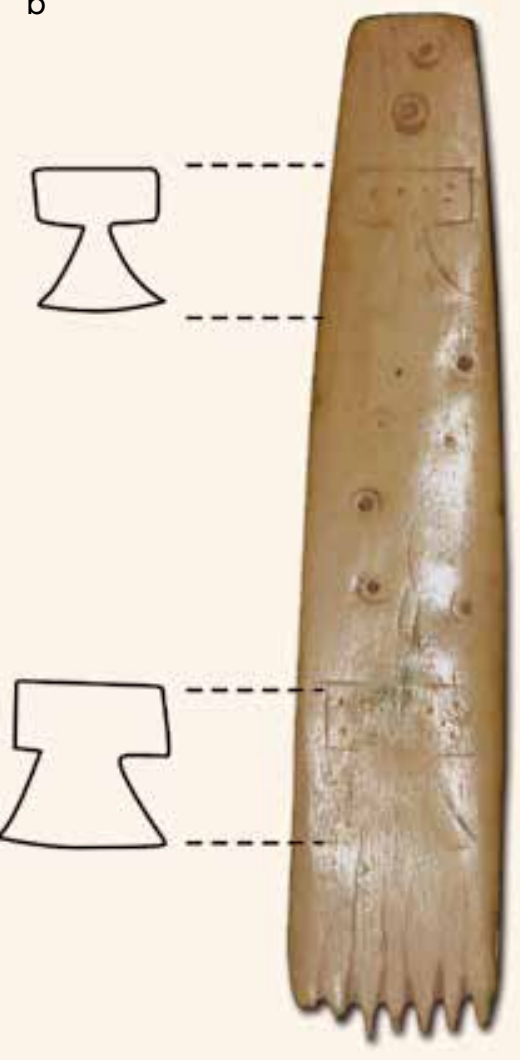

e

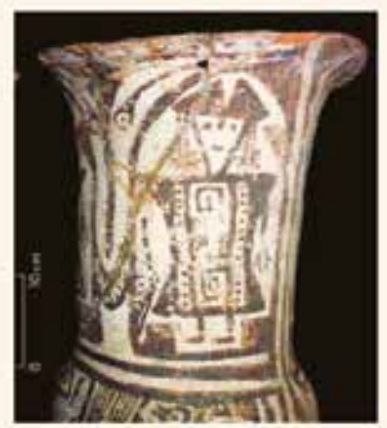

Figura 3. Objetos de arte mueble con escutiformes. a) calabaza pirograbada del río Loa, Museo Chileno de Arte Precolombino $\mathrm{N}^{\circ} 3123$ (tomado de Berenguer 2009), b) peine de hueso de Santa Rosa de Tastil (Museo de Antropología de Salta), c) disco de metal, Museo de La Plata No 6997 (tomado de González 1977), d) urna santamariana No 91-02-0777 (Museo de Antropología de Salta) y e) detalle urna santamariana con escutiforme No VC6494 de Fuerte Quemado, Ethnologisches Museum, Berlín (tomado de Nastri 2008).

Figure 3. Shield-shape art objects. a) Pyro-engraved gourd from the Loa River, Museo Chileno de Arte Precolombino $N^{\circ} 3123$ (from Berenguer 2009), b) Bone comb from Santa Rosa de Tastil (Museo de Antropología de Salta), c) Metal disc, Museo de La Plata $N^{\circ} 6997$ (from González 1977), d) Santa Maria urn No 91-02-0777 (Museo de Antropología de Salta) and e) Detail of a Santa Maria urn with shield-shape $N^{\circ}$ VC6494 from Fuerte Quemado, Ethnologisches Museum, Berlin (from Nastri 2008). 
de estos escudos debido a que no fueron hallados en los depósitos museísticos. La única pieza que guarda cierta similitud con la morfología de los escutiformes es el escudo ceremonial hallado como ajuar funerario en Angualasto (San Juan). Su forma general es de dos trapecios unidos por sus bases menores y su cara anterior está cubierta por un mosaico de malaquita y turquesa con un diseño en feldespato rojo (González 1967).

Como mencionamos, Aschero (2000) plantea la estrecha similitud de los escutiformes con las hachas de piedra o metal de doble hoja. Esta interpretación es ratificada por Montt \& Pimentel (2009), quienes refuerzan la similitud de las hachas con los escutiformes y señalan que estos serían personificaciones de hachas o directamente hombres hacha, descartando, de esta manera, su semejanza con los escudos. Recientemente, y en forma independiente, de Hoyos (2013) arriba a conclusiones semejantes luego de llevar a cabo un pormenorizado análisis comparativo entre representaciones de escutiformes rupestres de varios sitios del NOA con hachas de bronce y líticas de la misma área. ${ }^{4}$

Más allá de la interpretación de los diversos autores mencionados, la mayor parte de ellos reconoce que los escutiformes son motivos-iconos con alto contenido simbólico y emblemático, vinculados a individuos con poder. Parafraseando a Aschero (2000), los escutiformes serían una forma de metáforas visuales de ese poder. Nielsen (2007) ahonda aún más en los atributos de poder de los escutiformes y adhiere a la idea, siguiendo la interpretación de González (1977), de que estas imágenes representan guerreros. En un pormenorizado análisis observa que los mismos están íntimamente ligados a objetos utilizados durante los conflictos armados que tan frecuentemente enfrentaron a los distintos grupos étnicos durante el Tardío a lo largo y ancho del área circumpuneña. Entre estos objetos están las trompetas con diseños de escutiformes en su pabellón y las placas metálicas que frecuentemente presentan similar iconografía (fig. 3). Otros motivos relacionados con las acciones bélicas son las cabezas cercenadas, que también forman parte del repertorio iconográfico de discos de metal, hachas y campanas (Nielsen 2007) y urnas santamarianas (Nastri 2008). María de Hoyos, que también reconoce en los escutiformes a personificaciones de guerreros, retoma la discusión que tiene como eje la interpretación del escutiforme como hacha o como escudo y concluye que "exaltaría más las cualidades de un guerrero y provocaría un impacto más inquietante a un adversario la identificación de su portador con un arma ofensiva más que una defensiva" (2013: 459), inclinándose de esta manera a la interpretación del escutiforme como hacha.

\section{LA MICRORREGIÓN GUACHIPAS}

\section{Localización y caracterización ambiental}

Desde el año 1998, este equipo de trabajo ha abordado el estudio de las representaciones rupestres de la microrregión Guachipas, ubicada en el departamento homónimo en el centro de la provincia de Salta, NOA (fig. 4). Los soportes utilizados para la ejecución de las pinturas son aleros y abrigos labrados en un conjunto de sierras que forman parte de la cordillera Oriental (Turner \& Mon 1979). En términos geológicos, la roca soporte corresponde a areniscas rojas del subgrupo Pirgua (grupo Salta). Estas serranías presentan escarpadas cadenas montañosas separadas por valles profundos entre los que se cuentan el Calchaquí, por el Oeste, y el de Lerma, por el Norte.

Como mencionamos, se han definido dos sectores para el estudio de las pinturas rupestres del área: hacia el Norte, el sector Quebrada de Ablomé, actualmente adyacente al gran espejo de agua conformado por el dique Cabra Corral o General Belgrano y, hacia el sur, el sector Las Juntas separado del anterior por $40 \mathrm{~km}$ aproximadamente (ver mapa de fig. 4).

Ambos presentan una vegetación variada que responde a diferencias altitudinales. Por ejemplo, para acceder a los sitios próximos a Las Juntas se atraviesan diversos pisos, entre los cuales interesa destacar el de la selva montana o yungas a $1200 \mathrm{msnm}$ con un sector más bajo que es el del cebil (Anadenanthera colubrina var. cebil). El piso superior, que continúa al anterior, es el del aliso (Alnus acuminata) y prados subandinos, entre 1500 y $2500 \mathrm{msnm}$. Allí es donde se localiza el cerro Cuevas Pintadas, a $1800 \mathrm{msnm}$, la localidad con mayor cantidad de sitios con pinturas rupestres de la microrregión, próxima a los bosques de cebil de la cuesta del Cebilar (12 km) (figs. 4c y d). En los prados subandinos la vegetación se caracteriza por un pobre desarrollo arbóreo, presencia de matas arbustivas y una abundante extensión de herbáceas o pastizales, musgos y líquenes, un espacio geográfico muy apto para la práctica pastoril.

\section{Antecedentes de investigación}

Las primeras menciones sobre las pinturas del sector de la quebrada de Ablomé corresponden a Ambrosetti (1903), que se refiere a las pinturas de la quebrada de La Bodega (ABL3 y ABL7 de nuestra clasificación). Nueve décadas después, los trabajos en la región son reanudados por Navamuel (Navamuel 1997; Alonso et al. 2000) y continuados por el Museo de Antropología de 

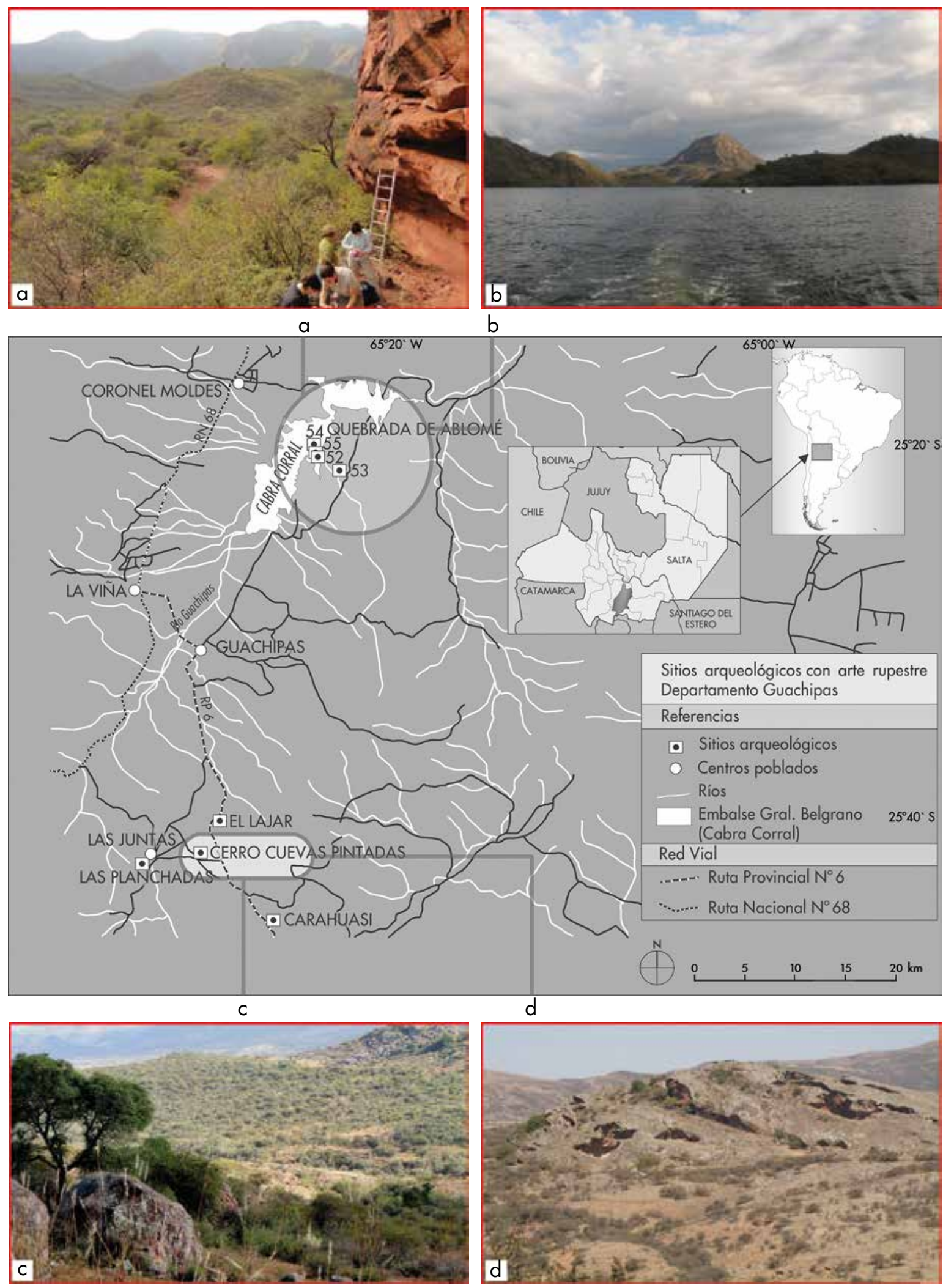

Figura 4. Mapa de sitios/localidades de la microrregión Guachipas; a) y b) Sector Quebrada de Ablomé; c) y d) Sector Las Juntas. Figure 4. Map of sites/localities in Guachipas microregion; a) and b) Quebrada de Ablomé Sector; c) and d) Las Juntas Sector. 
Salta, que queda a cargo del relevamiento de las pinturas juntamente con el Instituto Nacional de Antropología. María de Hoyos (2010, 2013), por su parte, realiza un pormenorizado análisis de los sitios La Bodega 1 y La Bodega 2 y Ablomé.

El sector sur de la microrregión (Las Juntas) también es objeto de investigaciones pioneras. Ambrosetti (1895) publica una descripción de la gruta pintada de Carahuasi junto con los dibujos realizados por Holmberg. Posteriormente, este autor realiza una extensa investigación arqueológica en Pampa Grande situada a $15 \mathrm{~km}$ al sur de Las Juntas, donde se recuperaron las urnas homónimas (Ambrosetti 1906). Las pinturas de Carahuasi son ampliamente tratadas por Quiroga a comienzos del siglo xx, si bien sus trabajos fueron editados recién en 1931 (Quiroga 1931). A partir de allí, este sitio aparece en múltiples oportunidades en la bibliografía especializada. Tiempo después, Aparicio (1944) describe la gruta pintada de El Lajar y un abrigo contiguo con grabados, ambos ubicados en la cuesta de El Lajar.

La localidad Cerro Cuevas Pintadas (en adelante CCP) fue reconocida en el ámbito científico en 1971 luego de la visita de Cigliano y colaboradores. A partir de un artículo periodístico (La Prensa 1971), CCP es integrado a los circuitos turísticos y simultáneamente se inicia un proceso de vandalismo que continúa actualmente. Luego, el Museo de Antropología de Salta se hace cargo de la documentación del arte rupestre de la localidad (Santillán 1991; Navamuel 1997), siendo Santoni \& Xamena (1995) los autores de un extenso informe centralizado en el alero Ambrosetti que permanece inédito.

Las investigaciones que enmarcan este trabajo se inician en 1998 con el propósito de documentar las pinturas juntamente con el diagnóstico de los procesos de deterioro que las afectan (Rolandi et al. 2002). Los trabajos incluyeron algunas acciones de planificación para el uso público, especialmente teniendo en cuenta que la localidad fue nominada Lugar Histórico Nacional en 1999 y que esta declaración podría promover la atracción turística. Durante esta etapa también se realizó el relevamiento original de Las Planchadas (Podestá et al. 2005) y se continúan y completan los de varios aleros de CCP además de Las Planchadas, cuesta del Lajar y Carahuasi. María de Hoyos (2013) incluye en su extenso trabajo sobre la figura humana en el arte rupestre del NOA las representaciones provenientes de varios aleros localizados en este sector (Las Planchadas, Alero Ambrosetti, Carahuasi, cuesta del Lajar).

\section{ARTE RUPESTRE DE LA MICRORREGIÓN GUACHIPAS}

\section{Características generales, sectores y sitios}

El arte rupestre de la microrregión Guachipas presenta una alta densidad de motivos pintados en los que se registra una gran diversidad de tipos abstractos y figurativos. Entre estos últimos se destacan: figuras humanas, con profusión de representaciones del uncu o túnica andina, además de escutiformes, camélidos, felinos, suris, cóndores, lagartos, serpientes y cánidos (fig. 5). No descartamos la existencia de representaciones de elementos topográficos como montañas (Quiroga 1931). Una característica distintiva del arte rupestre es la multiplicidad de escenas de alto contenido anecdótico, como escenas de caza, caravanas, tiro, enfrentamiento armado, cópula, así como también escenas rituales (fig. 6). Algunas de las escenas se encadenan en forma sucesiva adquiriendo un carácter de tipo narrativo (por ejemplo, una escena de sacrificio humano en el sitio ABL3). Esta peculiaridad otorga un carácter único a las pinturas de Guachipas dentro del contexto del arte rupestre del NOA.

En cuanto a la cronología de las pinturas se asumen diferentes momentos de ejecución de los motivos a partir de las superposiciones, reciclados y diferentes grados de desvaído registrados en las mismas. Además, se constatan algunos pocos casos de grabados abstractos más tempranos que las pinturas.

En lo referente a la tonalidad, se han registrado distintas variedades de rojo, negro, gris, blanco y rosado, además del amarillo. Según los resultados obtenidos de los análisis de difracción de rayos X (Canadian Conservation Institute, Ottawa), los diferentes tonos fueron preparados con pigmentos minerales como hematitas (rojo), yeso, hydroxiapatita y whewellita (blancos). También se registró un caso de uso de carbón vegetal en una pintura negra (Rolandi et al. 2002). El juego de figura-fondo, un recurso plástico de uso recurrente y exclusivo en los escutiformes, lleva a considerar también a la tonalidad natural de la roca como color involucrado en la composición de los motivos.

Como señalamos, el arte rupestre del área de estudio se presenta en dos sectores: al Norte comprende la localidad Quebrada de Ablomé y el sector sur próximo a Las Juntas, que incluye las localidades CCP y Cuesta del Lajar, además de los sitios Las Planchadas y Carahuasi (fig. 4).

Respecto de los soportes se destaca que el número de aleros con arte rupestre registrados en cada uno de los sitios/localidades mencionados es variable. Así, la localidad más grande es CCP, también denominada 

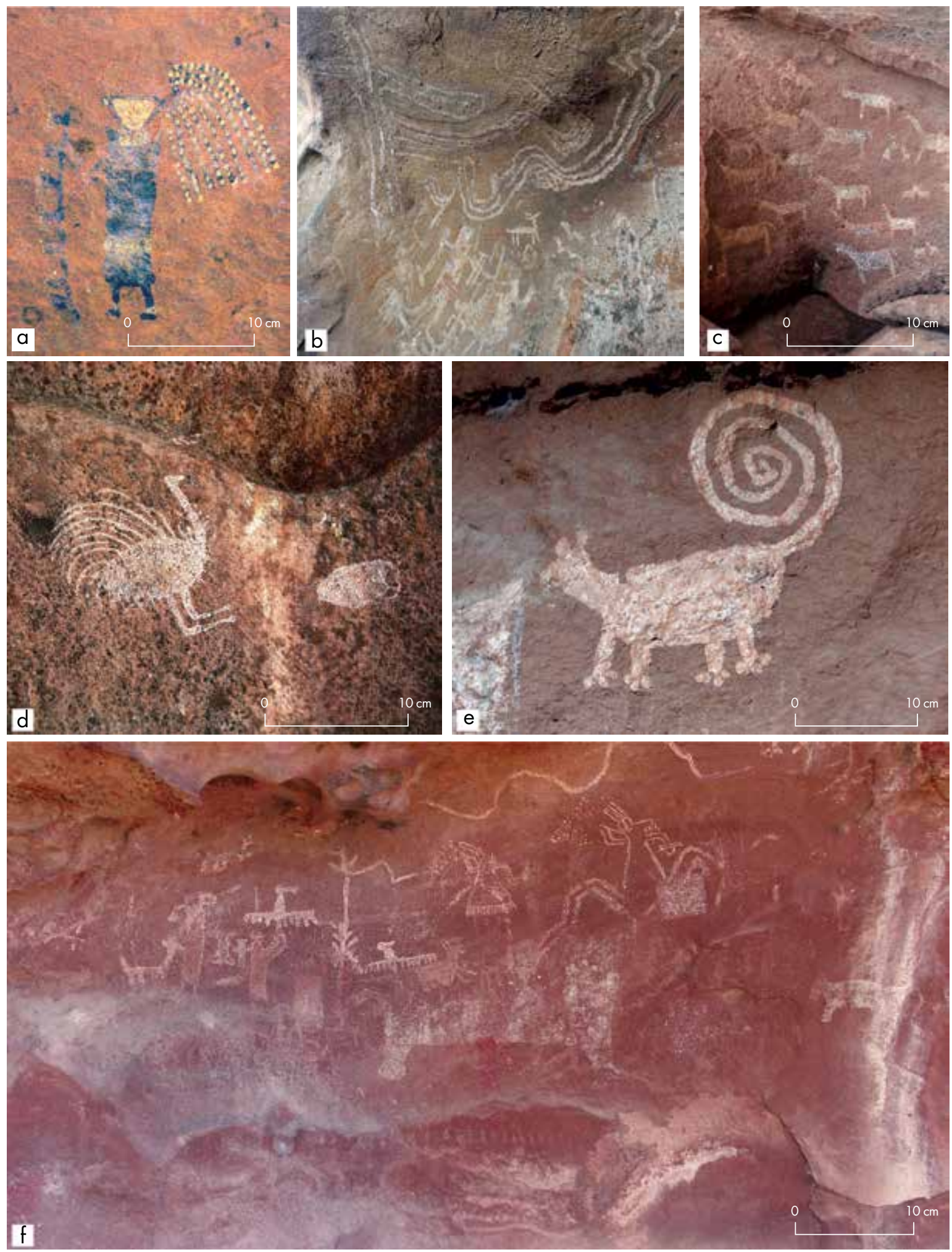

Figura 5. Arte rupestre de la microrregión Guachipas; a) personaje con vara emplumada y tocado (ABL 3) (foto con retoque digital); b) líneas sinuosas paralelas y otros motivos (CCP-Alero 8); c) camélidos agrupados (CCP-Alero 9); d) suri (CCP-Alero 14); e) felino (ABL 3) y f) Alero 7, CCP.

Figure 5. Rock art in Guachipas microregion; a) figure with feathered staff and headdress (ABL 3) (digitally enhanced photo); b) Wavy parallel lines and other motifs (CCP-Alero 8); c) Grouped camelids (CCP-Alero 9); d) Suri (CCP-Alero 14); e) Feline (ABL 3) andf) Alero 7, CCP. 

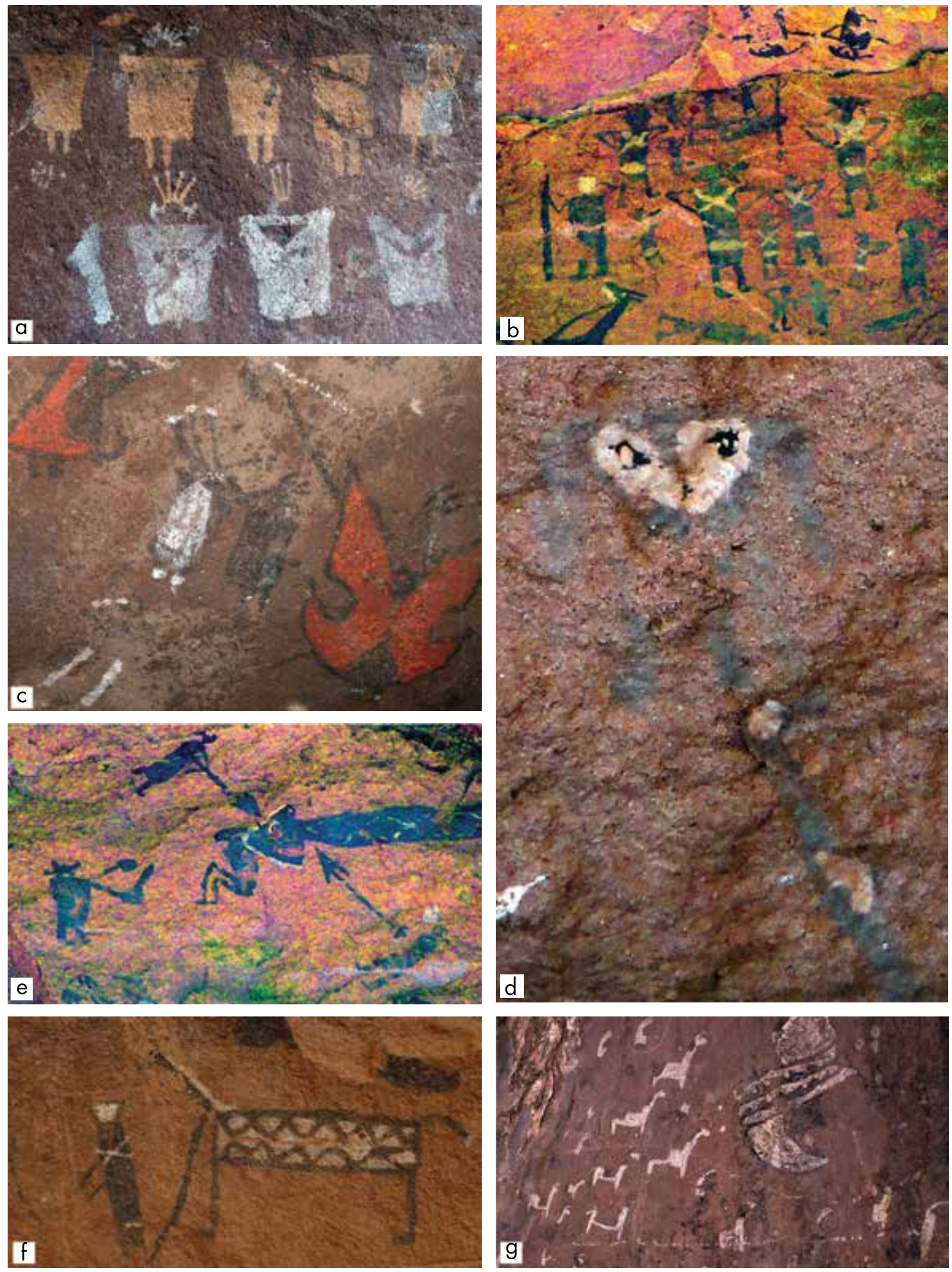

Figura 6. Escenas de la microrregión Guachipas; a) alineaciones de uncus con tocado (Cuesta del Lajar); b) escena ritual (ABL 3); c) escutiformes con arma (CCP-Alero Ambrosetti); d) cabeza cercenada (ABL 3); e) escena de sacrificio (ABL 3); f) escena de tiro (ABL 5) y g) escutiforme con camélidos alineados (CCP-Alero Ambrosetti). (Fotos con retoque digital: b, d y e).

Figure 6. Scenes from Guachipas microregion; a) rows of uncus with headdress (Cuesta de Lajar); b) ritual scene (ABL 3); c) shield-shape with weapon (CCP-Alero Ambrosetti); d) severed head (ABL 3); e) sacrificial scene (ABL 3); f) shoot scene (ABL 5) and g) shield-shape with line of camelids (CCP-Alero Ambrosetti). (Digitally enhanced photos: b, dy e). 
Pirguas del Sol, que se ubica a $4 \mathrm{~km}$ de Las Juntas. Se trata de un cerro que presenta la apariencia de una gran colina chata y redondeada. Frente al mismo se abre una amplia y extensa pampa con suave pendiente hacia el fondo del valle. Los 26 aleros identificados ${ }^{5}$ se concentran en la cara Norte y, en menor cantidad, en la cumbre y en la cara este del cerro (figs. 4c y d). La Quebrada de Ablomé es una localidad que comprende cinco sitios con arte rupestre (ABL1, ABL3, ABL5, ABL6 y ABL7). Las menores frecuencias se registran en la localidad Cuesta de El Lajar, con dos aleros, y Carahuasi y Las Planchadas, ambos con un solo alero con arte rupestre.

La muestra analizada hasta el momento, que no incluye el conteo total de motivos, asciende a 1292 motivos distribuidos en 35 sitios/aleros. En relación con la proporción de categorías de motivos se observa que predominan los tipos figurativos $(67,01 \%)$ por sobre los abstractos (32,9\%). Si bien la microrregión Guachipas cuenta con un repertorio muy variado, en esta oportunidad el análisis se centra en los escutiformes.

\section{Los escutiformes en Guachipas}

Cantidades, distribución y uso del soporte

Pasando específicamente al análisis de los escutiformes, se observa que los mismos constituyen aproximadamente el $20 \%$ del total, lo que permite señalar que se trata de una muestra amplia. Así, en el área de estudio se documentaron 257 motivos escutiformes que incluyen un total de 394 representaciones (Tabla 1) ${ }^{6}$. La mayor parte son motivos simples (81,54\%), si bien también se registraron casos de compuestos $(18,46 \%)$.

Respecto de su distribución, los escutiformes se encuentran presentes en todas las localidades/sitios mencionados, si bien en CCP se registraron escutiformes en 18 de los 26 aleros (Tabla 1). A pesar de esta amplia distribución, se observa que la misma es diferencial, ya que en dos localidades los escutiformes presentan frecuencias superiores a 100 (CCP y ABL), mientras que en las restantes las frecuencias son notablemente más bajas. Entre las primeras, se destacan los aleros ABL1 con 80 escutiformes y Ambrosetti (CCP) con 35.

En términos generales, los escutiformes se presentan en sitios de acceso fácil o de mediana dificultad (fig. 7). Dentro de los sitios, considerando particularmente los sectores en los cuales se ubican los escutiformes, se registra una gran variedad. En el caso particular del CCP, estos motivos están mayoritariamente representados en los aleros de la base y de la mitad del cerro en soportes verticales plano-cóncavos. En ocasiones se destacan de otras representaciones por su mayor tamaño y ubicación preferencial sobre la superficie rocosa. Por otra parte, en la quebrada de Ablomé hay sectores a gran altura (ABL 3) donde se registran pinturas a $5 \mathrm{~m}$ del piso (fig. $7 \mathrm{~b}$ ). También se registran sitios (ABL1 y Alero Ambrosetti-CCP) que presentan algunos sectores del soporte invisibles desde el exterior, en plano horizontal (sector techo) y a baja altura, presentando un acceso altamente restringido a un número limitado de observadores (4 o 5) que debe recostarse para apreciar los escutiformes y otros motivos asociados. Cabe mencionar que justamente en estos sectores de los aleros es donde se concentra una gran cantidad de escutiformes (los del Alero Ambrosetti y 23 representaciones del total registrado en ABL1), con un excelente estado de conservación por el resguardo que brinda el soporte (fig. 7c). Si se considera que la visibilidad se expresa en el alcance óptico de las pinturas de un sitio por la distancia máxima en la cual estas pueden ser percibidas (Lenssen-Erz 2004), en el caso de Guachipas se constata una amplia variabilidad.

Tabla 1. Cantidad de aleros, motivos escutiformes y representaciones documentados en la microrregión Guachipas. Table 1. Number of rock shelters, shield-shaped motifs and representations documented in Guachipas microregion.

\begin{tabular}{|c|c|c|c|}
\hline Sitios/Localidades & $\begin{array}{c}\text { N } \\
\text { Aleros con } \\
\text { escutiformes }\end{array}$ & N Motivos & N Representaciones \\
\hline Cerro Cuevas Pintadas & 18 & 101 & 164 \\
\hline Quebrada de Ablomé & 5 & 110 & 136 \\
\hline Carahuasi & 1 & 18 & 35 \\
\hline Cuesta del Lajar & 1 & 1 & 1 \\
\hline Las Planchadas & 1 & 27 & 58 \\
\hline TOTAL & 26 & 257 & 394 \\
\hline
\end{tabular}



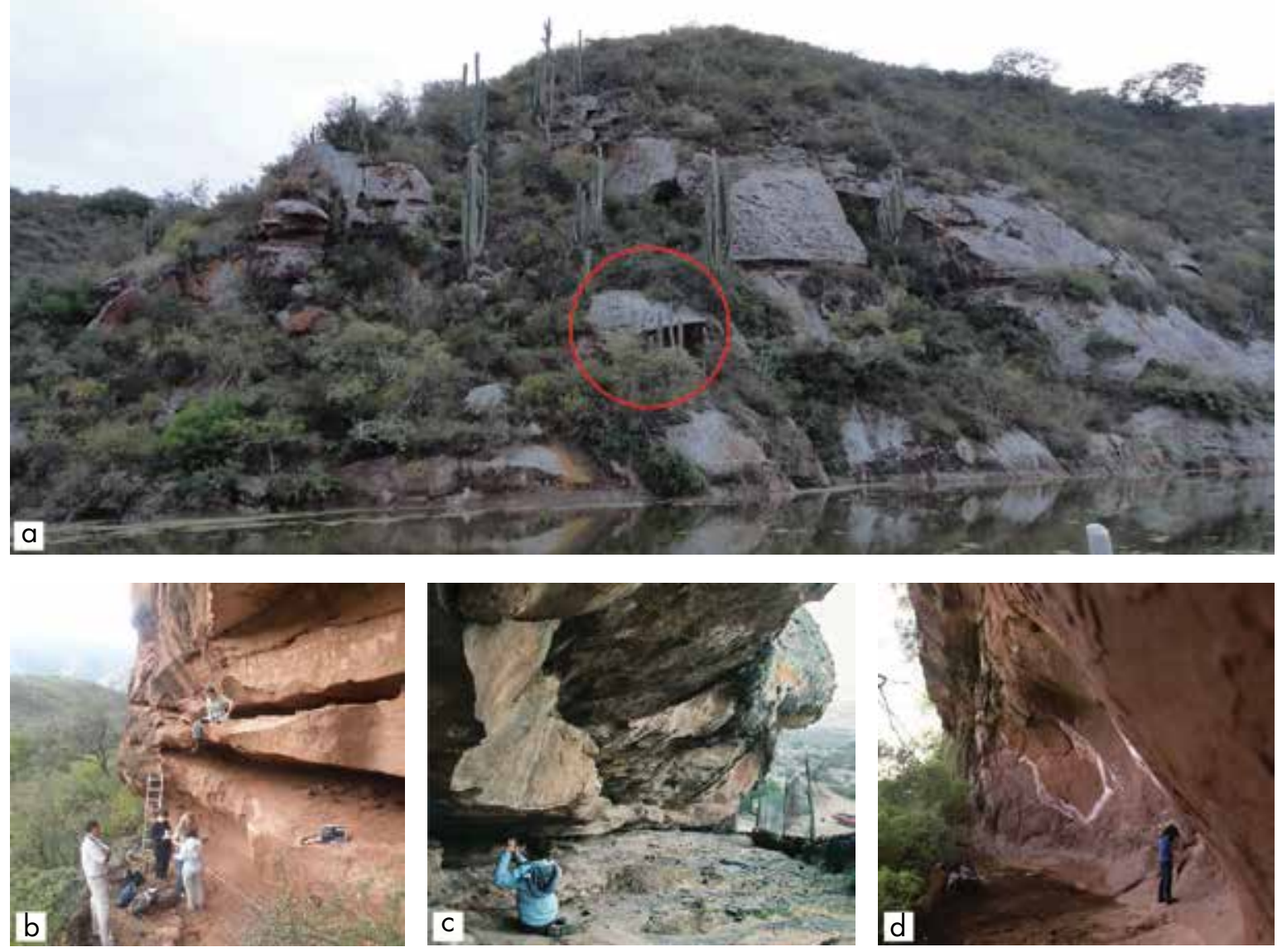

Figura 7. Diversidad de soportes; a) vista general ABL 5 sobre el Embalse Cabra Corral; b) ABL 3; c) Alero Ambrosetti (CCP) y d) Las Planchadas.

Figure 7. Different types of supports; a) overview of ABL 5 above Cabra Corral reservoir; b) ABL 3; c) Alero Ambrosetti (CCP) and d) Las Planchadas.

Categorías, contornos y diseños internos

Como mencionamos, los escutiformes se presentan mayoritariamente en motivos simples (81,54\%). En el caso de los motivos compuestos (18,46\%), los mismos se disponen en alineaciones horizontales que comparten la misma tonalidad -monocromías y bicromías-, pero no así diseños internos que los asemejen. Solo algunos casos presentan diseños internos iguales.

Las figuras se disponen de frente en la gran mayoría de los casos y presentan una gran diversidad de contornos (fig. 8). También se registran algunos pocos ejemplares que interpretamos como vistas de escutiformes de semiperfil.

De la gran variabilidad que caracteriza a estas representaciones, intentamos una descripción detallada de los escutiformes en lo que atañe a sus contornos. Comenzando desde el sector superior hacia el inferior, los bordes superiores son básicamente rectos (fig. 8, fila a) o cóncavos (fig. 8, b2, b3 y b4, fila c y fila d). Esta concavidad puede estar levemente esbozada o ser, contrariamente, muy pronunciada (fig. 8, b3 y d4). En algunos casos excepcionales, los ángulos superiores de los escutiformes se prolongan a tal extremo que alcanzan una posición vertical, definiendo un borde superior en U de líneas rectas (fig. 8, b1). En la interpretación de Aschero, esta forma especial representaría a un individuo con manos alzadas bajo una capa, poncho o vestimenta (patrón H4b, sensu Aschero 2000). Prosiguiendo la descripción a la mitad de la imagen, es aquí donde se registra la escotadura típica que define al escutiforme (patrón H4 en sentido estricto, Aschero 2000) (fig. 8, b3).

La angostura puede ser más o menos pronunciada (fig. 8, c2), curvilínea en la mayoría de los casos pero también rectilínea (fig. 8, a4) y combinada (fig. 8, a3 y c3). En cuanto a su ubicación, no siempre se encuentra hacia la mitad de la figura, pudiendo ocupar posiciones más cercanas al borde superior (fig. 8, d2 


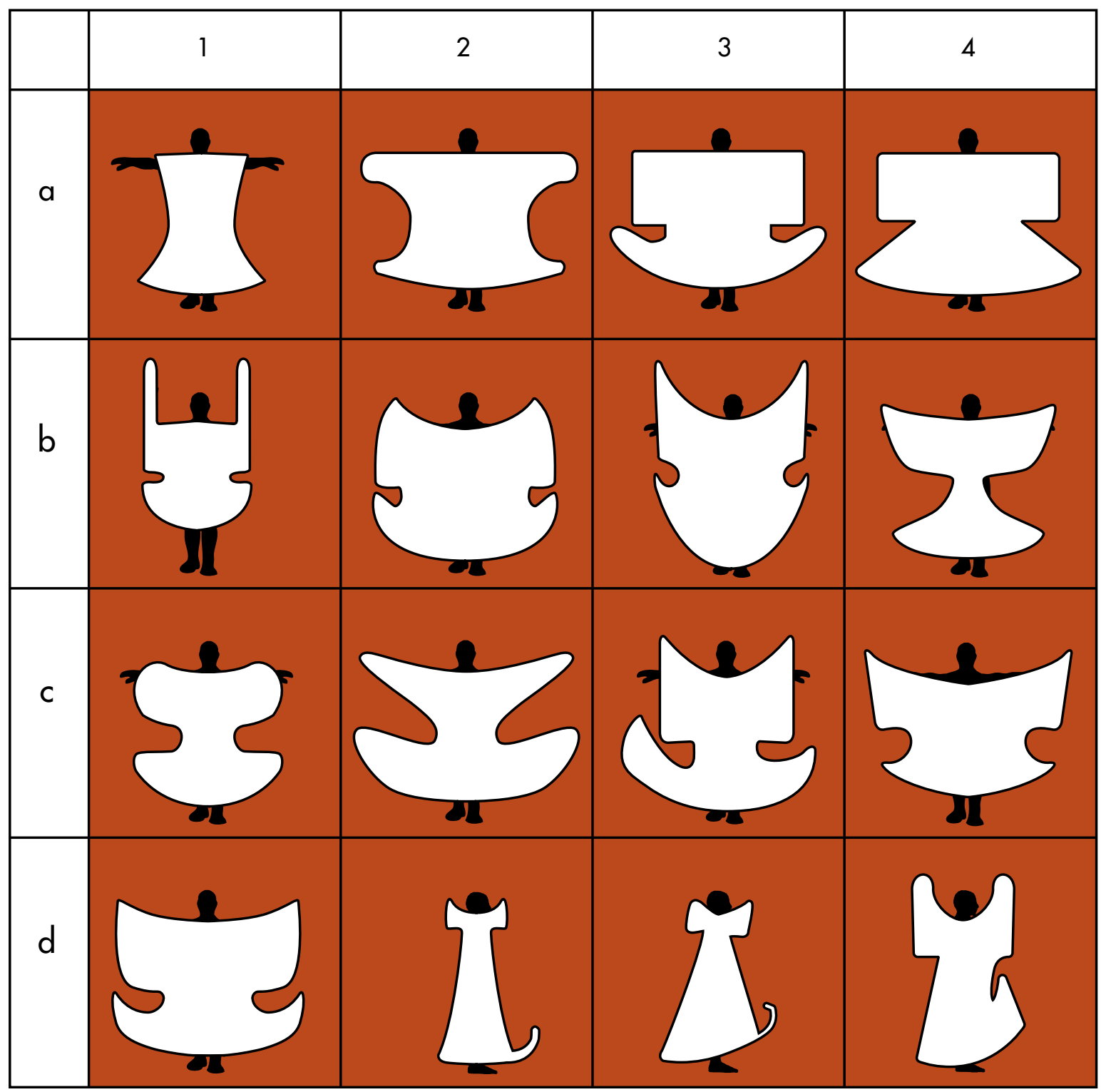

Figura 8. Diversidad de contornos.

Figure 8. Different types of borders.

y d3 interpretados como escutiformes en semiperfil) o inferior (fig. 8, c4). Las dimensiones de la escotadura difieren marcadamente en los distintos casos. Como mencionamos existen escutiformes que presentan una angostura apenas insinuada y otras, como algunos casos reportados en Chile, descritas como antropomorfos de lados cóncavos, que no presentan escotadura alguna (fig. 8, a1) (sensu Montt \& Pimentel 2009, ver también Troncoso 2011). Estas formas de escutiformes también se registran en Guachipas y se han presentado dificultades para establecer criterios para poder diferenciarlas de los uncus, característicos por su forma rectangular. De esta manera, en el conjunto total de motivos de Guachipas quedan algunas figuras categorizadas ambiguamente según su mayor grado de similitud con el uncu o el escutiforme. Por último, se registran los pocos casos de escutiformes de semiperfil, que son figuras más angostas, con la escotadura vista de frente y posicionada en la parte superior. Uno de los rasgos típicos de los escutiformes de semiperfil es que presentan solo uno de los extremos del borde inferior en forma prolongada y en gancho, morfología que dio lugar a su interpretación como personificaciones de hacha de gancho (Montt \& Pimentel 2009) (fig. 8, d2, d3 y d4). Por lo general, 
muestran ambos brazos en un solo lado de la figura portando armas u objetos y forman parte de hileras de personajes (ver más adelante fig. 9 b y 4).

Si bien desde el comienzo indicamos que los escutiformes tienen una clara connotación antropomorfa, llama la atención que, en términos de presencia/ausencia de rasgos del cuerpo humano o atuendos, observamos, por ejemplo, en el sector Quebrada de Ablomé el 42,73\% (N: 47) del total analizado presenta algún tipo de rasgo o atuendo (Tabla 2). ${ }^{7}$ Los rasgos del cuerpo humano son la cabeza y los brazos. En los casos de semiperfil
Tabla 2. Presencia/ausencia de rasgos humanos y atuendos en el sector Quebrada de Ablomé.

Table 2. Presence/absence of human traits and attire in the Quebrada de Ablomé sector.

\begin{tabular}{|c|c|c|}
\hline $\begin{array}{c}\text { Atributos humanos } \\
\text { en escutiformes }\end{array}$ & N & $\%$ \\
\hline Ausencia & 63 & $57,27 \%$ \\
\hline Presencia & 47 & $42,73 \%$ \\
\hline Total & 110 & 100 \\
\hline
\end{tabular}

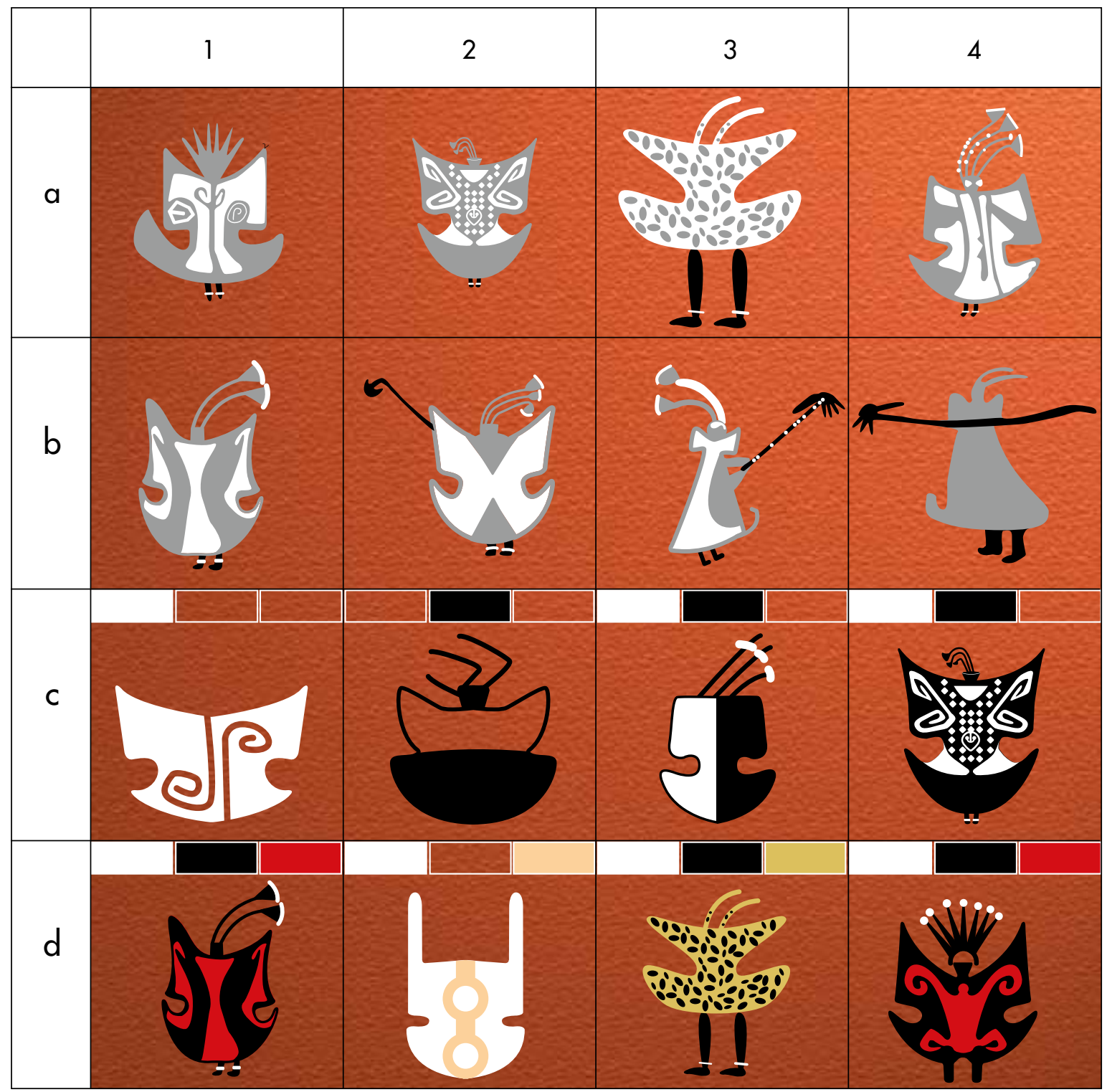

Figura 9. Presencia/ausencia de rasgos humanos y atuendos.

Figure 9. Presence/absence of human traits and attire. 


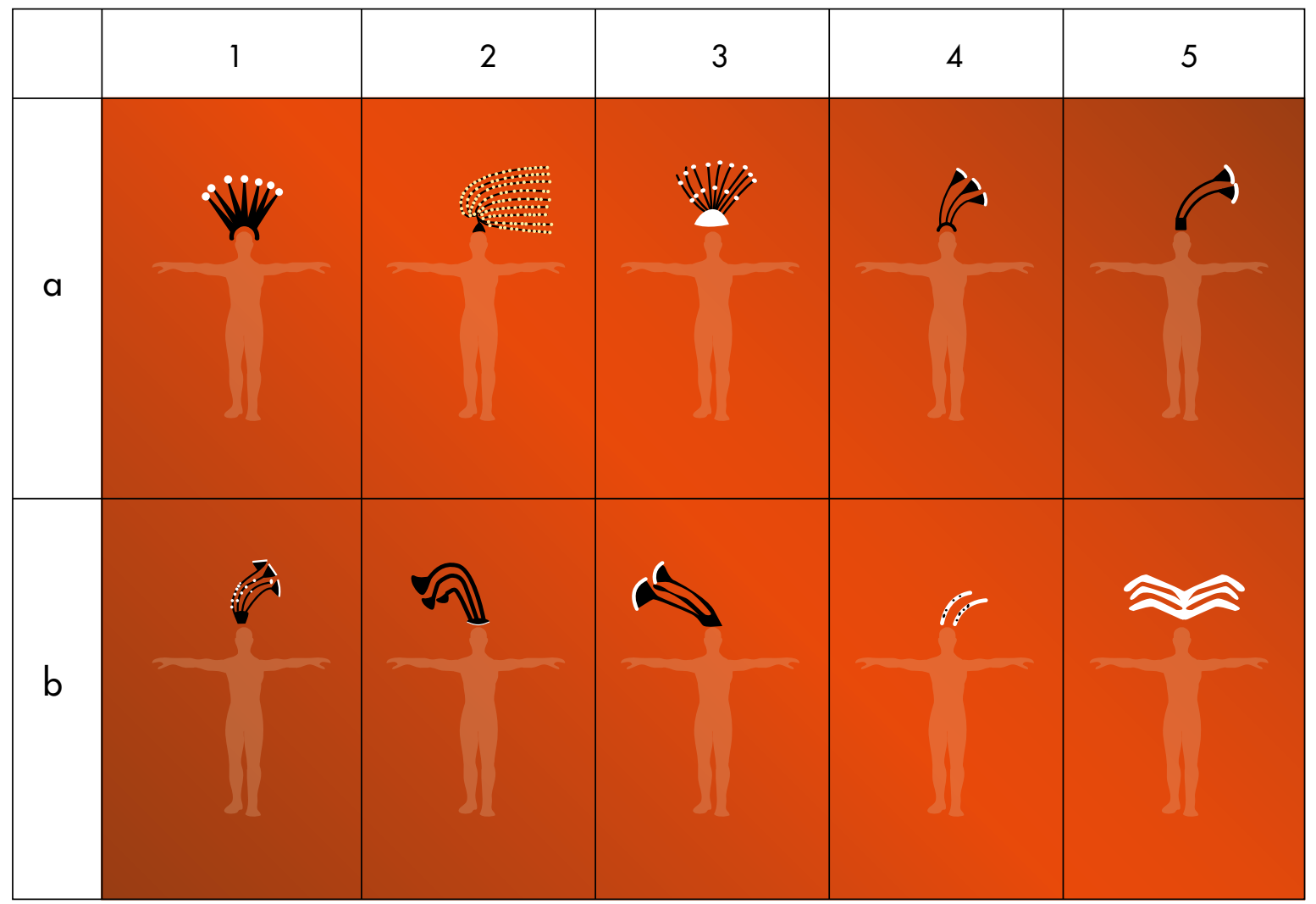

Figura 10. Tocados.

Figure 10. Headdresses.

solo encontramos manos, piernas y pies. Los atuendos incluyen la vestimenta y las armas. En la primera se diferencian los tocados (fig. 9, c2, c3 y c4 y d4) y las tobilleras (fig. 9, fila a y b1 y b2) y entre las armas se registran largas lanzas (fig. 9, b2, b3 y b4), algunas de ellas con terminaciones en forma de hacha de filo cóncavo (fig. 9, b2). Las figuras 9, c1 y 9, d2 ilustran ejemplos sin atributos humanos.

Los tocados son los que presentan la mayor diversidad morfológica y de tonalidad (fig. 10). Santoni \& Xamena (1995) registran en solo uno de los aleros de CCP (Ambrosetti) 23 tipos de adornos cefálicos realizados con plumas, si bien algunos de ellos corresponden a tocados de personajes con uncu. La mayoría de los tocados emplumados presentan entre dos y diez plumas pintadas con uno o dos tonos diferentes.

Los escutiformes difieren en su diseño interno, entre los más simples se registran los casos de escutiformes representados solamente a través de la línea de contorno y algunas figuras de tratamiento plano sin diseños internos (fig. 11, a1 y a3). Entre los escutiformes más elaborados existen también notorias diferencias. Los más simples presentan una división en campos (vertical, horizontal y diagonal) (fig. 11, a2, b1 y b2), mientras que los de mayor complejidad muestran una gran variación en la combinación de los diseños internos que, en algunos casos, presentan un contorneado en el sentido de perfilar la figura (figs. 9, 11 y 12). Otros incluyen figuras humanas en el interior, representadas a través del rostro o del cuerpo en forma parcial o completa (fig. 11, fila d y e2). Los escutiformes con diseños internos presentan motas, círculos, triángulos, algunos combinados con espiral, volutas y espirales, círculos alineados, entre otros elementos geométricos. Algunos de ellos, como las líneas en $\mathrm{X}$, ajedrezados y líneas con extremos en voluta remiten a diseños inkaicos. Todos ellos se disponen formando combinaciones de mayor o menor complejidad en las diferentes partes del escutiforme (fig. 11 b3, b4, c1, c3, c4, e1, f1, f2 y fig. 12). Muchos de los diseños descritos son recurrentes en las urnas santamarianas (fig. 2). En estas últimas también están presentes los escutiformes subdivididos en campos y las figuras de cabezas cercenadas, cuya morfología triangular se asemeja a la de algunos rostros que aparecen dentro del perímetro de los escutiformes (fig. 11 C3). Además de los escutiformes de factura completa, llama la atención la existencia de 


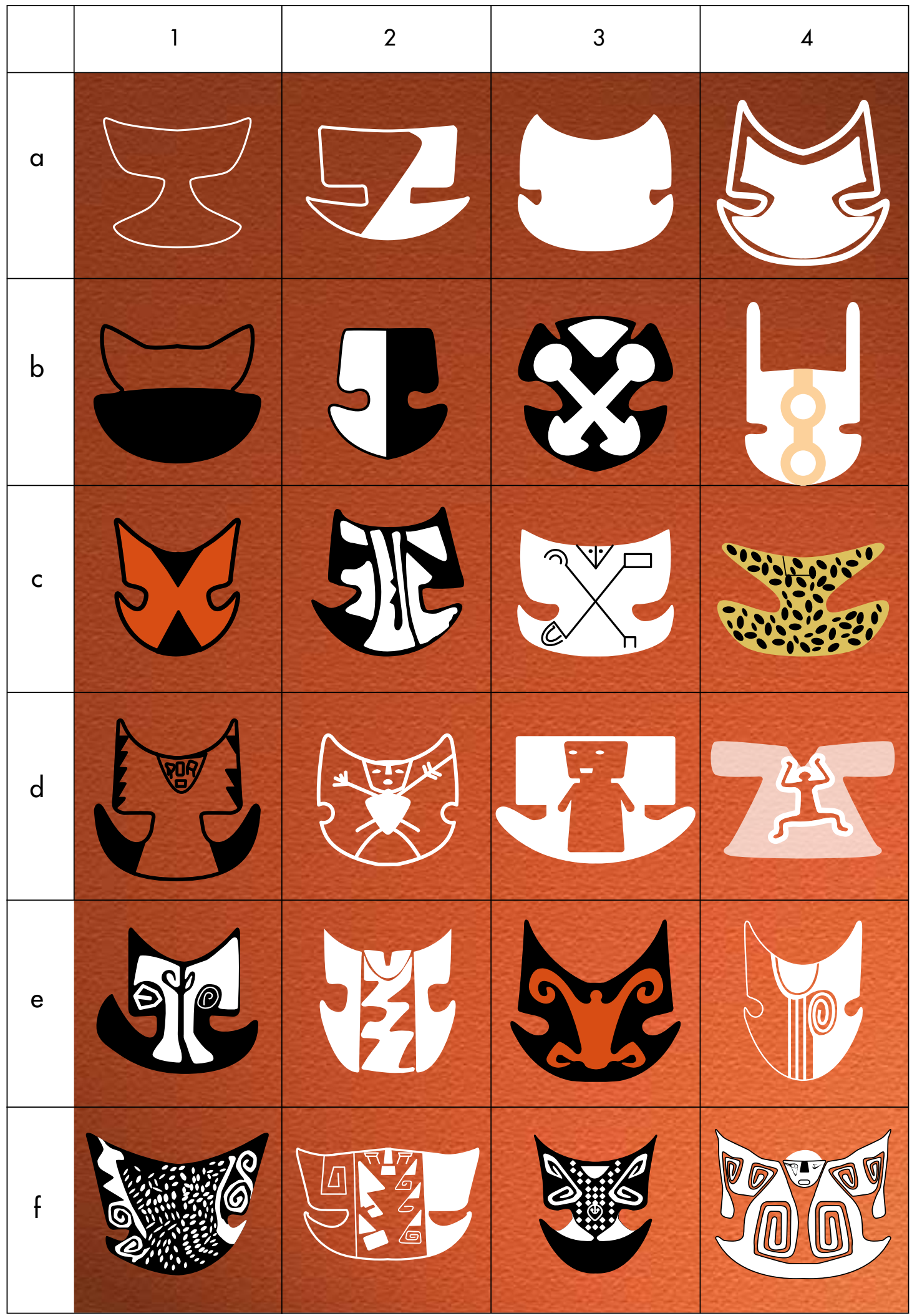

Figura 11. Diversidad de diseños internos.

Figure 11. Different types of internal designs. 

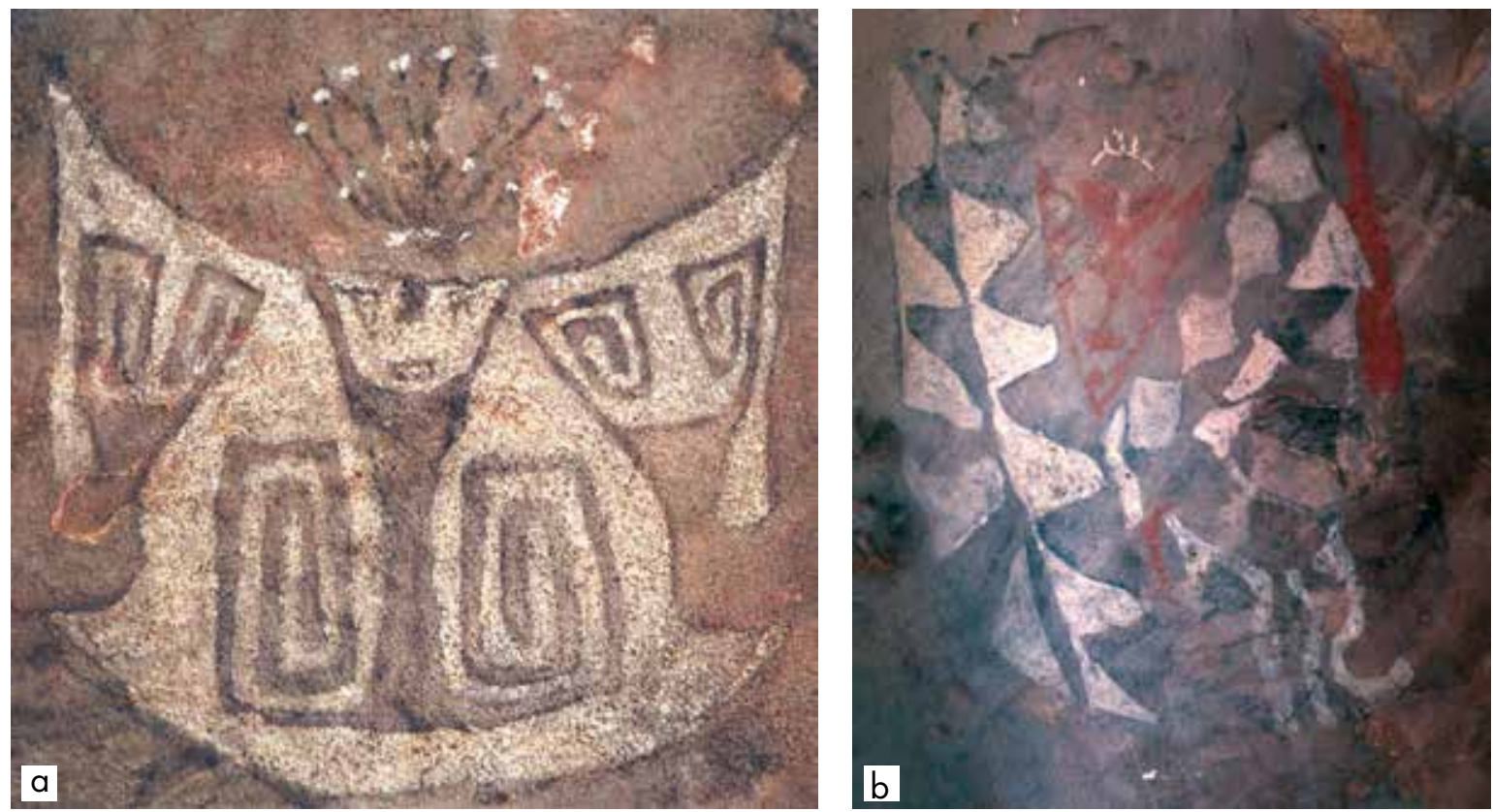

Figura 12. Escutiformes con diseño interno complejo y tocado, Alero Ambrosetti, CCP (fotos con retoque digital).

Figure 12. Shield-shapes with complex internal design and headdress, Alero Ambrosetti, CCP (digitally enhanced photos).

una escasa cantidad de representaciones inconclusas que facilita observar las diversas etapas que se encadenan en el diseño de estas figuras, un análisis ya emprendido por Pages (ver Santoni \& Xamena 1995).

\section{Dimensiones y tonalidades}

Los escutiformes se presentan en una gran variedad de dimensiones, predominando los clasificados como grandes (hasta $20 \times 20 \mathrm{~cm}$ ) con un $45,45 \%$, seguidos por los medianos (hasta $10 \times 10 \mathrm{~cm}$ ) con el 34,76\% (fig. 13). Se registran casos excepcionales de hasta 1,10 m de alto.

Si bien la literatura referida al tema destacó la policromía de los escutiformes, los presentes en la microrregión de estudio son principalmente monocromos $(56,64 \%)$ y hacen uso de diferentes tonalidades de amarillo y rojo, además de blanco, negro y gris (fig. 9 c1 y c2). También se ha documentado una gran cantidad de casos de bicromía, en los cuales se combinan los tonos mencionados (40,71\%), además de la tonalidad natural de la roca cuando se registra el juego de figura-fondo (fig. 9 c3, c4, d2). Los ejemplos registrados de policromía solo implican la combinación del blanco, rojo y negro que se registró en el Alero Ambrosetti de la localidad CCP $(2,65 \%)$ y un escutiforme en amarillo y negro con tobilleras blancas en ABL1 (fig. 9 d1, d3 y d4). Cabe destacar que la variedad de colores utilizados no se correlaciona necesariamente con la complejidad de los diseños. El tratamiento de las figuras puede ser lineal (19,57\%), plano $(52,17 \%)$ o lineal/plano (28,26\%) (fig. 11 a1, a3 y a4). Interesa destacar que dichas características no se combinan de un modo preestablecido, sino que juegan entre sí generando una amplísima variedad de efectos visuales. Esta multiplicidad lleva a reconocer una vez más que una gran parte de los escutiformes son ejemplares únicos dentro del inventario total de figuras de este tipo.

\section{Conjuntos y temas}

Los escutiformes de Guachipas se presentan aislados o en conjuntos tonales con otros tipos de motivos conformando una temática muy amplia. Primeramente, hay que destacar su asociación con camélidos agrupados o alineados como ocurre en Alero Ambrosetti y ABL3 (figs. $6 \mathrm{~g}$ y $14 \mathrm{~b}$ ). Estos últimos pueden estar formando parte de escenas de caravanas, si bien no hay claras evidencias de representaciones de carga sobre el lomo de los animales, con la excepción de algunas figuras de Carahuasi (Ambrosetti 1895). Los escutiformes también se asocian con figuras zoomorfas (fig. 14c), con otros escutiformes y, además, con representaciones de máscaras. Este último tipo de asociación (escutiformemáscara) se registra exclusivamente en dos diferentes sectores del sitio Las Planchadas. En uno de ellos (sector 1) se observan dos máscaras que conforman un mismo conjunto tonal (blanco) con varios escutiformes, además de presentar el mismo tipo de tratamiento de la figura (fig. 14d). Por otro lado, en la figura 2 se observan otras dos máscaras (sector 3) que no están 
directamente asociadas a escutiformes, como en el caso anterior, sino que son contemporáneas al primer momento de producción de una hilera de llamas. Es así que se observa que las cabezas y patas delanteras de los animales comparten similitud tonal y de tratamiento con las representaciones de máscaras. Esta alineación de camélidos fue repintada en un momento posterior (cuerpo y patas traseras) y completada con la figura de un caballo con su jinete que encabeza la hilera de animales. Se trata de la única representación registrada

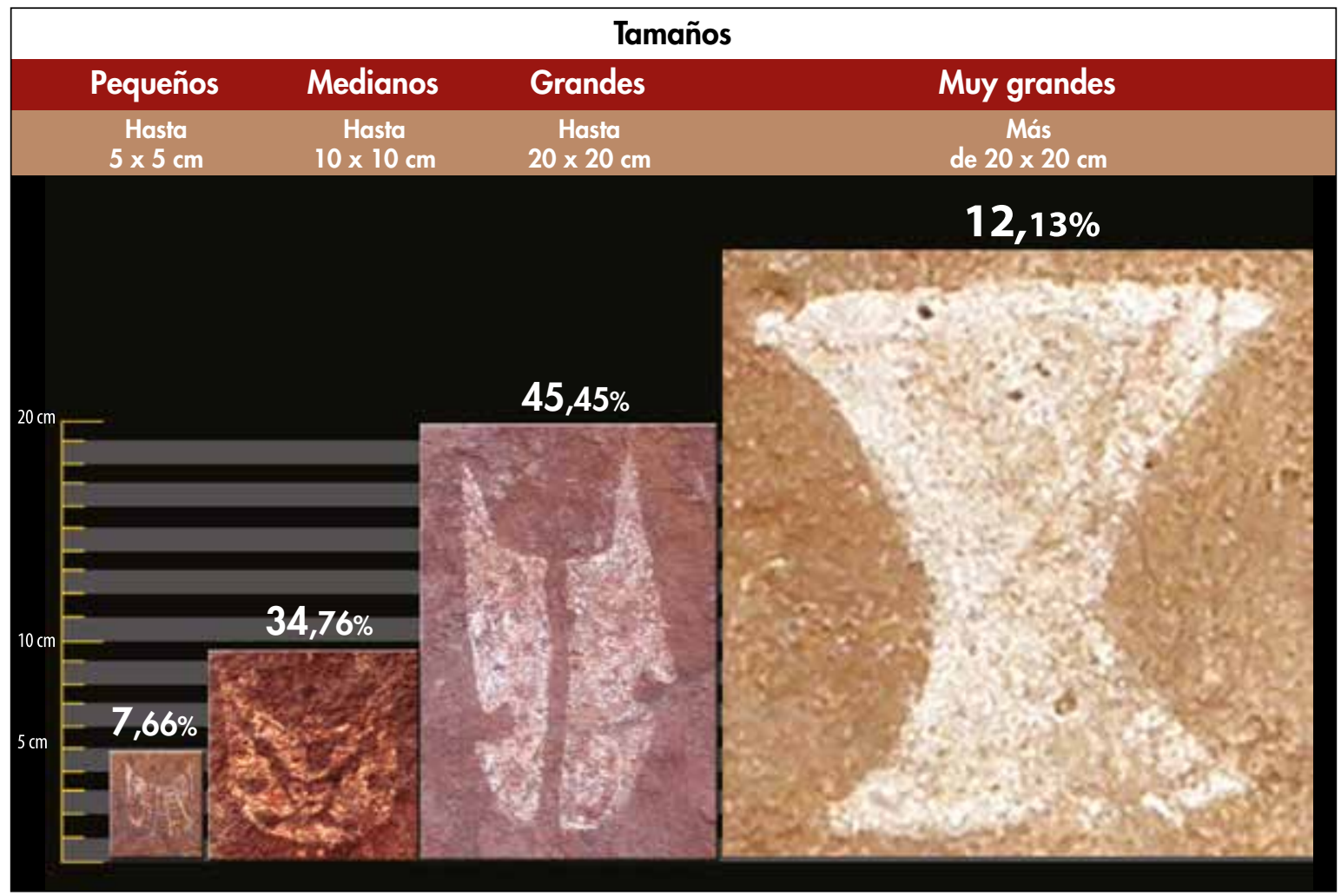

Figura 13. Dimensiones.

Figure 13. Dimensions.
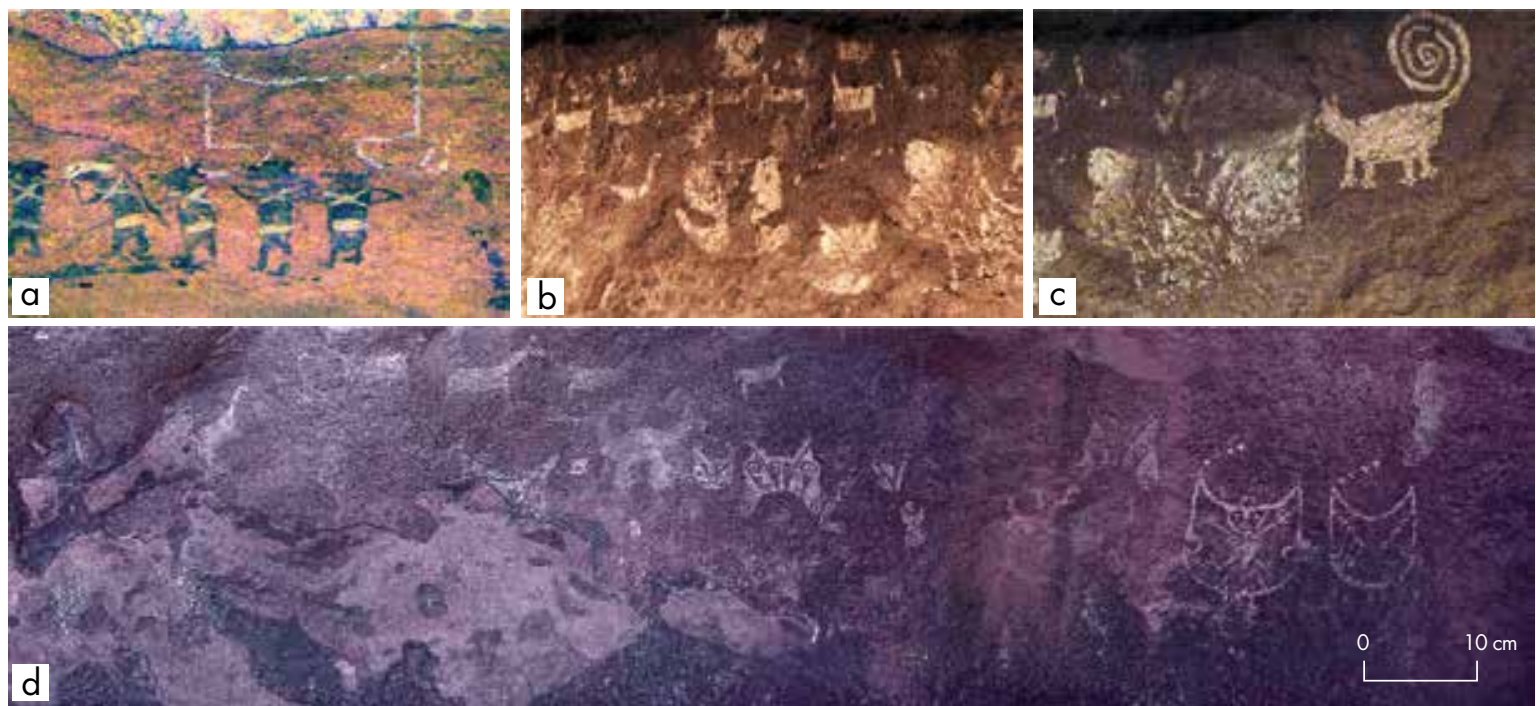

Figura 14. Temas; a), b) y c) ABL3; d) Las Planchadas (fotos con retoque digital).

Figure 14. Themes; a), b) and c) ABL3; d) Las Planchadas (digitally enhanced photos). 

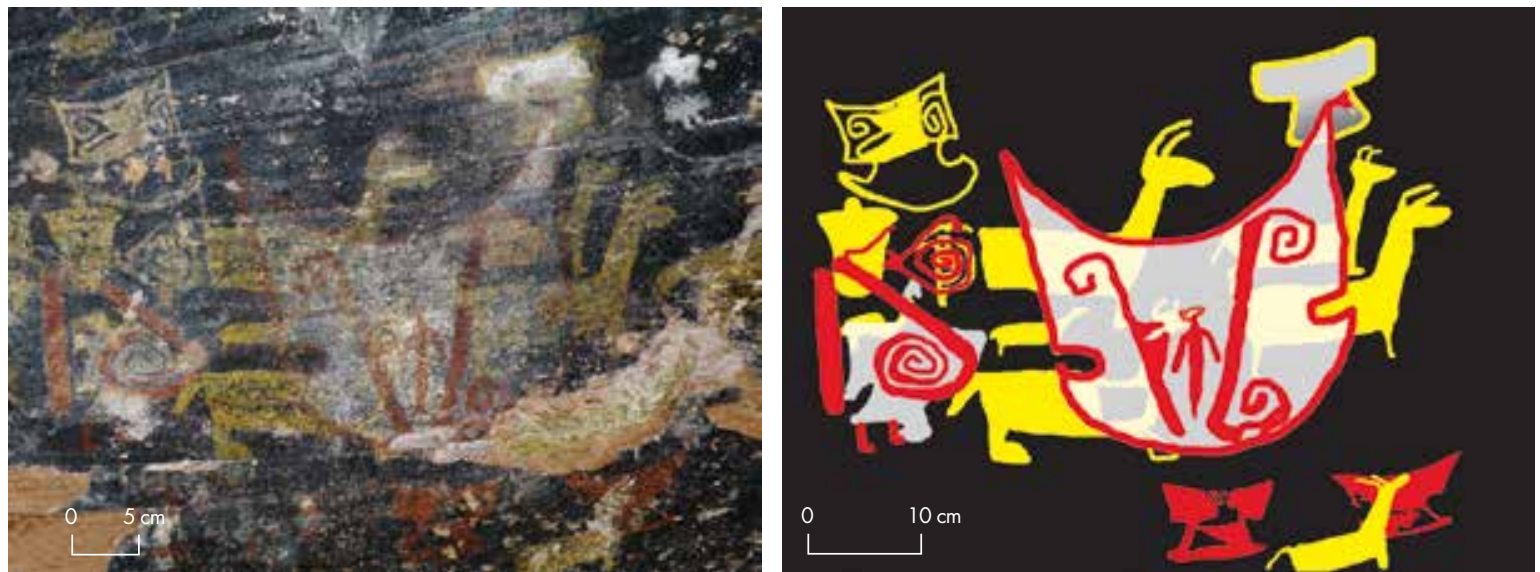

Figura 15. Superposición y efecto de transparencia registrados en Carahuasi.

Figure 15. Overlapping and transparency effect recorded at Carahuasi.

en el departamento de Guachipas de clara asignación al período hispano-indígena.

Las máscaras vuelven a marcar un grado de similitud muy grande con los diseños de las urnas santamarianas. En el sector superior de ambas representaciones que se ilustran en la figura 2 , se observa la forma de un "sobre-rostro", rasgo distintivo que Nastri (2008: figs. 6 a 10) identifica en el cuello de algunas urnas. La parte inferior de las máscaras de Las Planchadas es una intrincada composición figura-fondo conformada por diseños de triángulos con espiral, un tipo de combinación recurrente tanto en las urnas santamarianas como en los escutiformes de Guachipas. Por otro lado, interesa destacar también la estrecha semejanza que comparten los contornos de las máscaras de Las Planchadas y de los escutiformes, sobre todo si las primeras se aprecian luego de ser invertidas $180^{\circ}$ de su posición en el soporte (Podestá et al. 2005, láms. 22 y 23) (fig. 2). Todos estos rasgos permiten estrechar las semejanzas entre escutiformes y máscaras y sugerir la existencia de una simbología compartida de la que también forman parte las urnas santamarianas.

El repertorio temático de Guachipas se completa con las asociaciones de escutiformes con hileras de antropomorfos que son recurrentes y se presentan en una gran variedad de casos (fig. 14a). Por ejemplo, en Carahuasi se superponen a hileras de personajes con uncu (fig. 15) y en ABL3 adquieren una posición jerárquica respecto de hileras de antropomorfos (fig. 14a). Asimismo, se registra una menor cantidad de asociaciones con figuras humanas enfrentadas con armas (fig. 6c) (solo en pocos casos los escutiformes las presentan), además de escenas de caza, de sacrificio (fig. 6e) y cabezas trofeo (fig. 6d), en definitiva un repertorio muy amplio que en este trabajo solamente es esbozado.
Superposiciones

Se registra un total de 27 casos de superposiciones que involucran motivos escutiformes exclusivamente en el sector sur (Las Juntas) de la microrregión. De esta manera, teniendo en cuenta la cantidad de motivos analizados, se observa una baja tasa de superposiciones espacialmente restringida. La mitad de los casos (N: 13) se circunscriben a Carahuasi, mientras que los restantes se concentran en la localidad CCP (N: 10) y en Las Planchadas (N: 4). Se ha podido definir el orden de ejecución de las superposiciones en 22 casos, observándose que los escutiformes ocupan la posición inferior como superior en la misma proporción (Tabla 3). Los otros motivos que forman parte de las superposiciones, junto con los escutiformes, son figuras humanas, uncus, camélidos, cruces de contorno curvilíneo y trazos grabados, entre otros.

Los escutiformes incluidos en superposiciones presentan una gran variabilidad en términos del contorno general, morfología del borde superior, presencia/ausencia de atributos humanos y el predominio de aquellos de tamaño mediano y grande.

Cuando se considera la información de cada sitio/ localidad en particular, se observan ciertas singularidades que cabe mencionar. Por ejemplo, en Las Planchadas, a diferencia de lo observado en CCP y Carahuasi, los escutiformes ocupan solamente la posición inferior en las superposiciones consideradas.

En CCP y Carahuasi se destacan dos casos de superposiciones que involucran escutiformes sobre otros escutiformes. Interesa destacar el de este último sitio, donde se observa un escutiforme de tamaño muy grande con borde superior y escotaduras cóncavas con diseños internos, parcialmente superpuesto a otro de tamaño mediano con borde superior recto sin diseño 
Tabla 3. Superposiciones con orden definido de la microrregión Guachipas. Referencias: Zoo. = zoomorfo. Table 3. Overlapping motifs with defined order in the Guachipas microregion. Reference: Zoo.= zoomorphic.

\begin{tabular}{|c|c|c|c|}
\hline $\begin{array}{c}\text { Sitio/ } \\
\text { localidad }\end{array}$ & $\begin{array}{c}\text { Cantidad de } \\
\text { superposiciones }\end{array}$ & $\begin{array}{c}\text { Motivos en } \\
\text { posición superior }\end{array}$ & $\begin{array}{c}\text { Motivos en } \\
\text { posición inferior }\end{array}$ \\
\hline \multirow{4}{*}{$\begin{array}{l}\text { Las Planchadas } \\
\text { (LP) }\end{array}$} & 1 & Figura humana & Escutiforme \\
\hline & 2 & Camélido & Escutiforme \\
\hline & 3 & Felino & Escutiforme \\
\hline & 4 & Espiral & Escutiforme \\
\hline \multirow{8}{*}{$\begin{array}{c}\text { Cerro } \\
\text { Cuevas Pintadas } \\
\text { (CCP) }\end{array}$} & 1 & Escutiforme & Triángulos alineados \\
\hline & 2 & Escutiforme & Cruz de contorno curvilíneo \\
\hline & 3 & Escutiforme & Escutiforme \\
\hline & 4 & Uncu & Escutiforme \\
\hline & 5 & Escutiforme & Figura humana \\
\hline & 6 & Escutiforme & Círculo \\
\hline & 7 & Escutiforme & Zoo. indeterminado \\
\hline & 8 & Escutiforme & Trazos verticales (grabados) \\
\hline \multirow{10}{*}{ Carahuasi } & 1 & Escutiforme & Escutiforme \\
\hline & 2 & Escutiforme & Camélido \\
\hline & 3 & Escutiforme & Uncu \\
\hline & 4 & Camélido & Escutiforme \\
\hline & 5 & Escutiforme & Figura humana \\
\hline & 6 & Escutiforme & Figura humana \\
\hline & 7 & Camélido & Escutiforme \\
\hline & 8 & Escutiforme & Camélido \\
\hline & 9 & Camélido & Escutiforme \\
\hline & 10 & Camélido & Escutiforme \\
\hline
\end{tabular}

interno. Ninguno de ellos presenta atributos humanos (fig. 15). Los diseños de líneas con extremos en voluta que presenta el escutiforme ubicado en posición superior remiten a uno de los tipos básicos de tokapu inka establecidos por Thomas Barthel (1971) (citado por De Rojas Silva 2008).

De esta manera, tanto en CCP como en Carahuasi, la ejecución de escutiformes remite a diferentes momentos de las secuencias pictóricas del Tardío, lo que permite sostener la redundancia de su producción en el tiempo.

\section{RETOMANDO IDEAS Y PLANTEANDO EXPECTATIVAS}

En este artículo abordamos un tipo de representación, el escutiforme, recurrente en una amplia región del NOA y en una más acotada del Norte de Chile durante los momentos tardíos de la ocupación prehispánica que incluye la dominación inkaica. En la microrregión Guachipas observamos que la representación del escutiforme se reitera a lo largo del Tardío por medio de los casos de superposiciones consignados, que incluyen también figuras de escutiformes superpuestas. A pesar de contar con esta evidencia, aún no nos es posible precisar esta cronología, pero sí sugerir que esta representación no se interrumpe a lo largo del período considerado y que se encuentra presente durante el momento de la conquista inkaica. Algunos de los diseños internos de los escutiformes, tema que no pudimos abordar aquí detalladamente, remiten al tipo de decoración de vestimenta inkaica. Además, propusimos que la simbología del escutiforme podría alcanzar momentos hispano-indígenas, como quedó expresado en el sitio Las Planchadas.

Indicamos que los escutiformes en Guachipas tienen una presencia ubicua hallándose en todas las localidades con representaciones rupestres y en la gran mayoría de los sitios tratados, totalizando un $20 \%$ del corpus total 
de motivos. Dentro del extenso espacio circumpuneño argentino-chileno, es aquí donde se da la mayor concentración de este tipo de motivos.

Mencionamos su posición destacada respecto de otros motivos y enfatizamos su variada visibilidad sobre los soportes rocosos. Hicimos hincapié en dos aleros donde los escutiformes se ubican en sectores bajos con visibilidad restringida, de presentación muy privada (Lenssen-Erz 2004), sin por ello dejar de ostentar una posición realzada en relación con otros motivos. Un $22,5 \%$ de la muestra total de escutiformes analizada se encuentra bajo estas condiciones. Por un lado, esto plantea una restricción a la apreciación por parte de grupos numerosos. No obstante proponemos que, considerando todas las características en conjunto, expresa la intención de los ejecutores de lograr una preservación privilegiada de estas imágenes y, por lo tanto, su mayor perduración en comparación con la de otras pinturas que quedan excluidas de los soportes protegidos.

Otras características posicionan a los escutiformes como representaciones conspicuas dentro del conjunto de motivos de la microrregión. Estas particularidades incluyen una gran diversidad de contornos y dimensiones, amplia variedad de los diseños internos y tonalidades de pintura empleadas, así como el uso restringido de la policromía. Determinados recursos plásticos, en especial simetría, figura-fondo y contorneado, además de la transparencia, son de uso distintivo en la producción de escutiformes, así como también de las máscaras cuya morfología general asimilamos a la de los escutiformes (fig. 2). En términos generales, se observó una factura más cuidadosa en relación con otros tipos de motivos. Todas estas propiedades permiten inferir una importante inversión de trabajo en la mayor parte de los escutiformes.

Así, en estos motivos se sintetiza una serie de rasgos que son exclusivos en su comparación con el repertorio rupestre general. Su amplia variabilidad morfológica se aúna con la diversidad temática en las que el escutiforme interviene, dentro de la cual siempre adquiere una posición relevante (fig. 14 a, b y c). Su localización sobre el soporte muestra mayor jerarquía respecto de otros motivos asociados y expresa, en ocasiones, una clara intención de privilegiar la preservación de los escutiformes.

Somos conscientes de que estas particularidades estéticas, que tan notoriamente se vuelcan en los escutiformes, no son meras recurrencias sino que, por lo contrario, tienen un propósito bien definido desde el mismo momento en que el motivo rupestre fue concebido. Así, todas estas cualidades permiten caracterizar a los escutiformes como imágenes estéticamente resonantes.
Como planteamos en la introducción, el arte rupestre tiene la capacidad, en comparación con otros aspectos del registro arqueológico, de impactar en un grupo mayor de gente. Sin embargo, destacamos la necesidad de considerar las características de cada conjunto de representaciones, a fin de evaluar si este es el caso en las imágenes bajo estudio. Luego del análisis realizado, sostenemos que los escutiformes de la microrregión Guachipas efectivamente presentan una serie de características que refuerzan aún más ese potencial dentro del conjunto general de representaciones rupestres del NOA. Es notorio que estas imágenes buscaron dejar una impronta sensorial en las personas que las observaron y justamente esta idea es la que conduce a indagar sobre el valor y el rol específico que estas cumplieron dentro del contexto social donde fueron creadas (ver al respecto Gosden 2001).

Su extensa dispersión por el NOA y en sectores acotados del Norte de Chile durante momentos prehispánicos tardíos, además de la amplitud de soportes -más allá del rupestre- sobre los cuales se plasma, realza a esta representación como una significante visual de alto contenido simbólico. De tal manera, estas características, sumadas a las propiedades estéticas que presentan, como se evidenció en el área de estudio, en lo relativo a su emplazamiento, morfología y dimensiones, etc., sugieren que fueron elaboradas con la intención de ser observadas por un grupo amplio de personas, que en nuestro caso correspondería a pastores y caravaneros. Así, se plantea que probablemente expresaron cuestiones de índole sociopolítica. Por otra parte, la gran variabilidad registrada en la microrregión Guachipas apunta a la riqueza de contenido simbólico que conllevan estas figuras.

Revisando las diferentes interpretaciones que durante más de cien años se entretejieron alrededor de los escutiformes, aceptamos la idea generalizada de que se trata de figuras humanas $-y$ no simplemente de sus vestimentas- que representan individuos que surgen de la nueva jerarquía social del Tardío en los Andes centro-sur y que concentran en sí mismos altos niveles de estatus, prestigio y poder.

La identificación con estos personajes es coherente con el cambio socioeconómico ocurrido durante los Desarrollos Regionales. Este Período se relaciona "con la concentración del poder de decisión en individuos o elites que habrían ejercido un progresivo control sobre la producción agrícola y pastoril" (Aschero 2000: 18), una situación que se habría iniciado ya en momentos previos al Tardío. Siguiendo a Aschero, esta nueva situación posiciona a jefes y curacas en la órbita del poder y, a partir de ese momento, son estos los individuos que establecen las nuevas estrategias para la producción agropastoril 
y ejercen el control sobre el tráfico caravanero. Para el caso específico de Guachipas sostenemos la hipótesis de que en esta microrregión, dada su aptitud para la práctica pastoril, se concentraría una cantidad de sitios de descanso de caravanas. Estos lugares combinarían asentamientos vinculados al pastoreo local y áreas de campamento reiterado y relativamente prolongado de tropas en viaje. Producto de esta interacción se llevarían a cabo prácticas rituales enmarcadas en una cosmovisión ampliamente compartida por los pastores circumpuneños a partir de la negociación entre caravaneros en tránsito, grupos locales y sus autoridades/deidades en torno a los derechos sobre el aprovechamiento de recursos (pasto, leña, agua, cebil, etc.) (Nielsen 1997).

En el caso de Guachipas, cobra especial interés la localidad CCP, uno de los repositorios con representaciones de escutiformes más densos, no solo en cuanto a la cantidad de sitios, sino también de representaciones. Dada la vecindad de CCP con los bosques de cebil, es factible pensar que el control ejercido por la nueva jerarquía social también recayó sobre los ámbitos de procedencia de la principal especie alucinógena utilizada en prácticas ceremoniales en el NOA y norte de Chile. CCP pudo haber jugado un rol particular en este contexto, debido a que se trata de la zona más próxima y accesible para su adquisición desde ambientes de puna (ver al respecto Aschero 2000; Santoni \& Xamena 1995), y esta cercanía facilitaría el control y la obtención rápida y eficaz de este alucinógeno. No sería entonces casual la recurrencia de escutiformes en CCP y en otros sitios próximos como Carahuasi y Las Planchadas. En suma, tratamos con un tipo de representación que aparece y se repite en momentos donde se manifiesta una mayor complejidad social y competencia intergrupal en conjunto con una ampliación de las redes de interacción regional que incluyó también el intercambio de sustancias alucinógenas.

En este contexto político-social, es razonable aceptar que los escutiformes con atributos humanos o sin ellos representan a personajes jerárquicos, como jefes, curacas y guerreros, como fue sugerido anteriormente (Ambrosetti 1895; Quiroga 1931; González 1977; Aschero 2000 , entre otros). Los tocados emplumados y las armas que portan estas figuras -tal como se manifiesta en la iconografía de las urnas santamarianas-, entre las cuales se destacan las hachas, son indicadores de la alta jerarquía de estos personajes, como fue señalado por los primeros investigadores que los describieron (Ambrosetti 1895; Quiroga 1931).

Los casos de escutiformes sin rasgos corporales ni objetos portables, referidos en el acápite Conjuntos y temas, que en Guachipas alcanzan un 60\% del total de estas representaciones, requieren un comentario particular. La ausencia de rasgos humanos en los escutiformes convierte a estas representaciones en una suerte de imágenes mnémicas altamente consustanciadas con la imagen del hacha de alto poder simbólico en el área que tratamos. Esto conduce a que estas representaciones se conviertan en íconos independientes de la figura humana, pero no por ello dejan de remitir a esta. Un análisis similar realizó Aschero en relación con los ancoriformes y las figuras de las hachas del arte rupestre del Tardío en la circumpuna (Aschero 2000). Esta interpretación también coincide con la propuesta de Montt \& Pimentel (2009) cuando refieren los escutiformes a formas de hombreshacha. En definitiva, la simbiosis hacha-figura humana no es más que una vieja propuesta de Ambrosetti (1903) que aúna dos imágenes de alto poder simbólico para reforzar aún más el poder de la imagen resultante.

De esta manera, tanto las investigaciones previas como el análisis aquí presentado apoyan la idea de que los escutiformes tienen una carga simbólica de magnitud. De allí que no sorprende que algunas de estas manifestaciones se hallen en lugares muy distanciados y fuera de los ámbitos circumpuneños, operando como marcas étnicas o emblemáticas en el paisaje (Aschero 2000: 36). El caso mencionado del valle de Illapel es buen ejemplo de ello y coincidimos con el autor que considera a estas representaciones como "significantes visuales con un importante capital simbólico” (Troncoso 2011: 228).

Como se planteó previamente, uno de los aportes de este trabajo es evidenciar la gran variabilidad observada en los escutiformes, ya que las casi 400 representaciones son diseños únicos e irrepetibles, con la salvedad de algunos pocos motivos compuestos que muestran semejanza entre sí. Esta diversidad no es exclusiva de los escutiformes de la microrregión Guachipas, sino que es compartida con otros sitios del NOA y Norte de Chile. Nos preguntamos acerca del porqué de esta diversidad y esto nos lleva a revisar la propuesta de Dowson (1998) en su análisis de las pinturas rupestres dentro del contexto de creencias Bushman (sur de África), donde observa que ciertas imágenes participan activamente en las prácticas sociopolíticas en las cuales están inmersas. El autor se refiere a un motivo altamente idiosincrático, el rain-making, que adquiere una amplia diversidad morfológica y compositiva en su representación. La diversidad es explicada como una búsqueda de notoriedad por parte del individuo (el chamán), que produce y manipula una imagen que le es propia y que, por lo tanto, busca diferenciarse de la de los demás, a fin de expresar su estatus frente a otros individuos de su contexto social (Dowson 1998: 85-87). Si bien la propuesta de Dowson puede ser el inicio de 
una explicación para comprender la diversidad de los escutiformes de Guachipas -en el entendimiento que los escutiformes son representaciones resonantes creadas por individuos que buscan a través de la ejecución de imágenes posicionarse en esferas de poder-, somos conscientes de que debemos indagar aún más en estos temas de cuestiones identitarias y demarcadores territoriales.

Al haber abordado el análisis de los escutiformes de la microrregión Guachipas cumplimos parcialmente con una vieja deuda, que es la de presentar al público un corpus iconográfico sobresaliente dentro del arte rupestre del NOA, que se encontraba prácticamente inédito. A pesar de ello, son varios los temas que quedan por encarar, como, por ejemplo, la riquísima información etnohistórica sobre la temática, la que permitirá aportar en el significado de las representaciones y escenas en las cuales los escutiformes intervienen como protagonistas. Asimismo, queda pendiente explorar otras variables en el estudio de los motivos escutiformes, avanzar en la comparación con las restantes imágenes realizadas en el Tardío y, por último, considerar las restantes líneas de evidencia que sean abordadas a medida que continúen las investigaciones. En el futuro intentaremos profundizar en temas que fueron meramente anunciados en esta primera presentación de los escutiformes de Guachipas, entre ellos la función que estos cumplieron como expresiones de identidad y de demarcación territorial. Estos y otros interrogantes irán guiando nuevos aportes en la temática.

RECONOCIMIENTOS A quienes colaboraron en las diferentes etapas del trabajo en Guachipas: Luis Santillán, David Guzmán, Mario Lazarovich, Raúl Mahr, Anabella Vasini, Irene Meninato. A la cuidadora de Pirguas del Sol, Victoria Quiroz y a la Policía Lacustre de Salta por sus atentos servicios. A Diana Costa Ríos, María Inés Diez, Sonia Escudero y Guadalupe Cernusco por su colaboración y apoyo logístico. Un especial reconocimiento a Thomas Heyd y a los evaluadores por sus buenos consejos.

\section{NOTAS}

1 En el término Tardío englobamos los Períodos de Desarrollos Regionales e Inka (y los respectivos utilizados en Chile), además de los momentos más tempranos del Hispano-Indígena.

2 Vale aclarar que no se han hallado escutiformes en Perú ni en Bolivia (Rainer Hostnig y Matthias Strecker com. pers.).

3 Adoptamos momentáneamente el nombre de máscara ante la falta de otro término más apropiado para describir estas imágenes, peculiares y novedosas en el arte rupestre, que aluden a un diseño que cubre el rostro y parte del cuerpo de una imagen antropomorfa. Podría tratarse de pintura facial-corporal.

4 María de Hoyos defiende su tesis doctoral sobre la figura humana en el arte rupestre del NOA en agosto del 2013, coincidiendo con el momento de concluir el presente artículo. Debido a este motivo no hemos podido incorporar mucha de la exhaustiva información sobre los escutiformes que ella presenta.

5 La prospección realizada en los últimos años por nuestro equipo permitió identificar 26 aleros, pero el conteo llevado a cabo por Santoni y Xamena (1995) sumó 33 aleros.
$6 \mathrm{Al}$ respecto coincidimos con Aschero y Martel que consideran que la representación y el motivo se entienden "como conceptos que operan en pasos distintos del análisis del contenido de un sitio de arte rupestre". La representación "tiene que ver con la segmentación inicial que el analista realiza al observar la superficie del soporte" y "que visualiza como unidades discretas (separadas unas de otras en el espacio del soporte) y que fueron producidas por un gesto técnico completo". El motivo "tiene que ver con los vínculos que el analista discrimina entre las representaciones: articulaciones por inclusión, ligaduras, vínculos anecdóticos, etc." (Aschero \& Martel 2003-2005: 50).

7 El término atuendo alude a la vestimenta y a todo tipo de ornamentación, tocado y objetos portados por la figura humana (sensu Montt 2005: 73).

\section{REFERENCIAS}

Alonso, R. N.; E. Navamuel \& E. Taruselli, 2000. Cabra Corral. Geología-Arqueología-Historia. Salta: Gráfica Editora.

Ambrosetti, J. B., 1895. Las grutas pintadas y los petroglifos de la provincia de Salta. Boletín del Instituto Geográfico Argentino XVI: 311-342.

— 1903. Cuatro pictografías de la región Calchaquí. Anales de la Sociedad Científica Argentina 56: 3-13. Buenos Aires: Sociedad Científica Argentina.

- 1904. Apuntes sobre la arqueología de la puna de Atacama. Revista del Museo de La Plata 12: 1-30.

- 1906. Exploraciones arqueológicas en la Pampa Grande (Provincia de Salta). Publicaciones de la Sección Antropológica 1: 1-198. Facultad de Filosofía y Letras.

Aparicio, F. DE, 1944. La Gruta Pintada de El Lajar (Departamento de Guachipas, provincia de Salta). Relaciones de la Sociedad Argentina de Antropología 4: 79-83.

Aschero, C. A., 1979. Aportes al estudio del arte rupestre de Inca Cueva-1 (Departamento de Humahuaca, Jujuy). En Actas de las Jornadas de Arqueología del Noroeste Argentino, pp. 419-459. Buenos Aires: Universidad del Salvador.

- 2000. Figuras humanas, camélidos y espacios en la interacción circumpuneña. En Arte en las rocas. Arte rupestre, menbires y piedras de colores en la Argentina, M. M. Podestá \& M. de Hoyos, Eds., pp. 15-44. Buenos Aires.

Aschero, C. \& Á. Martel, 2003-2005. El arte rupestre de Curuto-5, Antofagasta de la Sierra (Catamarca, Argentina). Cuadernos del Instituto Nacional de Antropología y Pensamiento Latinoamericano 20: 47-72.

Berenguer, J., 2004a. Caravanas, interacción y cambio en el desierto de Atacama. Santiago de Chile: Sirawi.

_ 2004b. Cinco milenios de arte rupestre en los Andes atacameños: Imágenes para lo humano, imágenes para lo divino. Boletín del Museo Chileno de Arte Precolombino 9: 75-108.

— 2009. Caravaneros y guerreros en el arte rupestre de Santa Bárbara, Alto Loa. En Crónicas sobre la piedra, arte rupestre de las Américas, M. Sepúlveda, L. Briones \& J. Chacama, Eds., pp. 193-203. Arica: Universidad de Tarapacá.

Boman, E., 1908. Antiquités de la Región Andine de la République Argentine et du Dessert d'Atacama. París: Imprimerie Nationale.

Cruz, P. \& R. JARA, 2011. Por encima de las nubes. Caminos, santuarios y arte rupestre en la serranía de Calilegua (Jujuy, Argentina). Comechingonia 14: 75-96.

De Rojas Silva, D. V., 2008. Los tokapu. Graficación de la emblemática inka. Colección Patrimonio. La Paz: Producciones CIMA Editores.

Dowson, T. A., 1998. Rain in Bushman belief, politics and history: The rock-art of rain-making in the south-eastern mountains, southern Africa. En The Archaeology of Rock-Art, C. Chippindale \& P. Taçon, Eds., pp. 73-89. Cambridge: Cambridge University Press.

FALCHI, M. P., 1994. Arte rupestre del periodo Agro-Alfarero Tardío en la región de Antofagasta de la Sierra. Provincia de Catamarca (Rep. Argentina). Boletín SIARB 8: 40-54. 
Fernández Distel, A., 2001. Catálogo del arte rupestre. Jujuy y su región. Buenos Aires: Dunken.

GonzÁlez, A. R., 1967 Una excepcional pieza de mosaico del N. O. argentino. Etnia 6: 1-28.

— 1977. Arte precolombino de la Argentina. Introducción a su bistoria cultural. Buenos Aires: Editorial Valero.

Gosden, C., 2001. Making sense: archaeology and aesthetics. World Archaeology 33 (2): 163-167.

HeYD, T., 2003. Rock art, aesthetics and cultural appropiation. The Journal of Aesthetics and Art Criticism 61 (1): 37-46.

— 2012. Rock "Art" and Art. Why aesthetics should matter. En A Companion to Rock Art, J. McDonald \& P. Veth, Eds., pp. 276-293. Chichester: Blackwell Publishing.

Hoyos, M. DE, 2010. La Bodega, un espacio plástico en el oriente de Salta. En Arqueología Argentina en el Bicentenario de la Revolución de Mayo, Tomo V, R. Bárcena \& H. Chiavazza, Eds., pp. 2077-2082. Universidad Nacional de Cuyo, Facultad de Filosofía y Letras, Instituto de Ciencias Humanas, Sociales y Ambientales.

2013. Cuerpos imaginados. Variaciones en la representación de la figura humana en el arte rupestre de la zona valliserrana del noroeste argentino. Tesis para optar al grado de Doctor en Arqueología, Facultad de Filosofía y Letras, Universidad de Buenos Aires.

LA PRENSA, 1971. Hallaron en Salta pinturas rupestres hechas por indígenas hace siglos. La Prensa, 27 de junio de 1971.

Lenssen-Erz, T., 2004. The setting of rock painting sites in the Branberg. En The figured landscapes of rock art. Looking at pictures in place, C. Chippindale \& G. Nash, Eds., pp. 131-150. Cambridge: Cambridge University Press.

LoRANDI, A. M., 1966. El arte rupestre del noroeste argentino (área del Norte de La Rioja y sur y centro de Catamarca). Dédalo. Revista de Arte é Arqueología. Museo de Arte e Arqueología II (4): 15-171.

LEDESMA, R. \& C. SUBELZA, 2012. Cerámica y arte rupestre en Cafayate. Un enfoque arqueológico. Salta: Editorial de la Universidad Nacional de Salta. [En prensa].

Martel, Á., 2009. Arte rupestre: Construcción y significación del espacio en la puna meridional argentina (Antofagasta de la Sierra, Catamarca). En Crónicas sobre la Piedra, arte rupestre de las Américas, M. Sepúlveda, L. Briones \& J. Chacama, Eds., pp. 271-280. Arica: Universidad de Tarapacá.

— 2010. Arte rupestre de pastores y caravaneros: Estudio contextual de las representaciones rupestres durante el Período Agroalfarero tardío (900-1480 DC) en el Noroeste argentino. Tesis para optar al grado de Doctor en Arqueología, Universidad de Buenos Aires.

Meninato, I., 2008. El arte rupestre en Tastil. Estudio reinterpretativo. Tesis de para optar al grado de Licenciado en Antropología, Universidad Nacional de Salta.

MontT, I., 2005. Vestimenta en la cultura visual Tardía del desierto de Atacama. Tesis para título de Arqueóloga, Departamento de Antropología, Universidad de Chile.

Montt, I. \& G. Pimentel, 2009. Grabados antropomorfos tardíos. El caso de las personificaciones de hachas en San Pedro de
Atacama (norte de Chile). En Crónicas sobre la Piedra, arte rupestre de las Américas. M. Sepúlveda, L. Briones \& J. Chacama, Eds., pp. 221-234. Arica: Universidad de Tarapacá.

Muscio, H. J., 2010. Representaciones rupestres tardías en Morritos, San Antonio de Los Cobres, Puna de Salta. Observaciones e hipótesis preliminares. Comechingonia 13: 115-119.

NASTRI, J., 2008. La figura de las largas cejas de la iconografía santamariana. Chamanismo, sacrificio y cosmovisión calchaquí. Boletín del Museo Chileno de Arte Precolombino 13 (1): 9-34.

NaVAmuel, E., 1997. Arte rupestre de Salta. En Actas de las Jornadas Internacionales de Arte Rupestre. "El rastro más antiguo de la espiritualidad humana". Salta, Octubre de 1997. <http:// www.rupestre.com.ar/articulos/rup03.htm > [Citado 18-02-2013].

NielSen, A., 1997. El tráfico caravanero visto desde La Jara. Estudios Atacameños 14: 339-371.

— 2007. Armas significantes: tramas culturales, guerra y cambio social en el sur andino prehispánico. Boletín del Museo Chileno de Arte Precolombino 12 (1): 9-41.

PALMA, J. R., 1997-1998. Ceremonialismo mortuorio y religioso arqueológico: Apuntes sobre complejidad social. Relaciones de la Sociedad Argentina de Antropología 22-23: 179-202.

Podestá, M. M., 1986-1987. Arte rupestre en asentamientos de cazadores-recolectores y agroalfareros en la Puna Sur de Argentina: Antofagasta de la Sierra, Catamarca. Relaciones de la Sociedad Argentina de Antropología 16 (1): 241-163.

Podestá, M. M.; D. Rolandi \& M. SÁNCHeZ Proaño, 2005. Arte rupestre de Argentina indígena. Noroeste. Buenos Aires: GAC, Academia Nacional de la Historia.

Quiroga, A., 1931. Petrografías y pictografías de Calchaquí. Buenos Aires: Universidad Nacional de Tucumán.

Rolandi, D.; M. M. Podestá, M. Sánchez Proaño \& A. Re, 2002. Procesos de deterioro y diagnóstico del grado de preservación de sitios con pinturas rupestres: el caso de Las Juntas (Guachipas, provincia de Salta). En Documento y registro del arte rupestre 6. Contribuciones al arte rupestre sudamericano, F. Taboada \& M. Strecker, Eds., pp. 94-108. Bolivia: SIARB.

Ruz, M. \& D. CHOROLQue, 2007. Arte rupestre del Pukara de Rinconada. una historia visual. Jujuy: Universidad Nacional de Jujuy.

SANTILLÁN, L., 1991 Ms. Informe preliminar "Las Juntas" (Departamento de Guachipas).

SAntoni, M. \& M. XAMENA, 1995 Ms. Pirguas del sol. Espacios sagrados y pinturas rupestres en Guachipas, Salta, Argentina.

TARragó, M. N., 2000. Chacras y Pukara. Desarrollos Sociales tardíos. En Nueva Historia Argentina. Los pueblos originarios y la Conquista, M. N. Tarragó Ed., pp. 257-300. Buenos Aires: Sudamericana.

Turner, J. C. \& R. Mon, 1979. Cordillera Oriental. En Actas del Segundo Simposio de la Academia Nacional de Ciencias de Córdoba, Vol. I, pp. 57-95. Córdoba.

Troncoso, A., 2011. Personajes fuera de lugar: antropomorfos tardíos en el arte rupestre del norte semiárido de Chile. Intersecciones en Antropología 12: 221-230.

Williams, V.; M. P. Villeggas, M. S. GhegGi \& M. G. Chaparro, 2005. Hospitalidad e intercambio en los valles mesotermales del noroeste argentino. Boletín de Arqueología PUCP 9: 335-372. 